Document downloaded from:

http://hdl.handle.net/10251/47376

This paper must be cited as:

Bannier, E.; Darut, G.; Sánchez, E.; Denoirjean, A.; Bordes, M.; Salvador Moya, MD.; Rayón Encinas, E.... (2011). Microstructure and photocatalytic activity of suspension plasma sprayed $\mathrm{TiO} 2$ coatings on steel and glass substrates. Surface and Coatings Technology. 206(2):378-386. doi:10.1016/j.surfcoat.2011.07.039

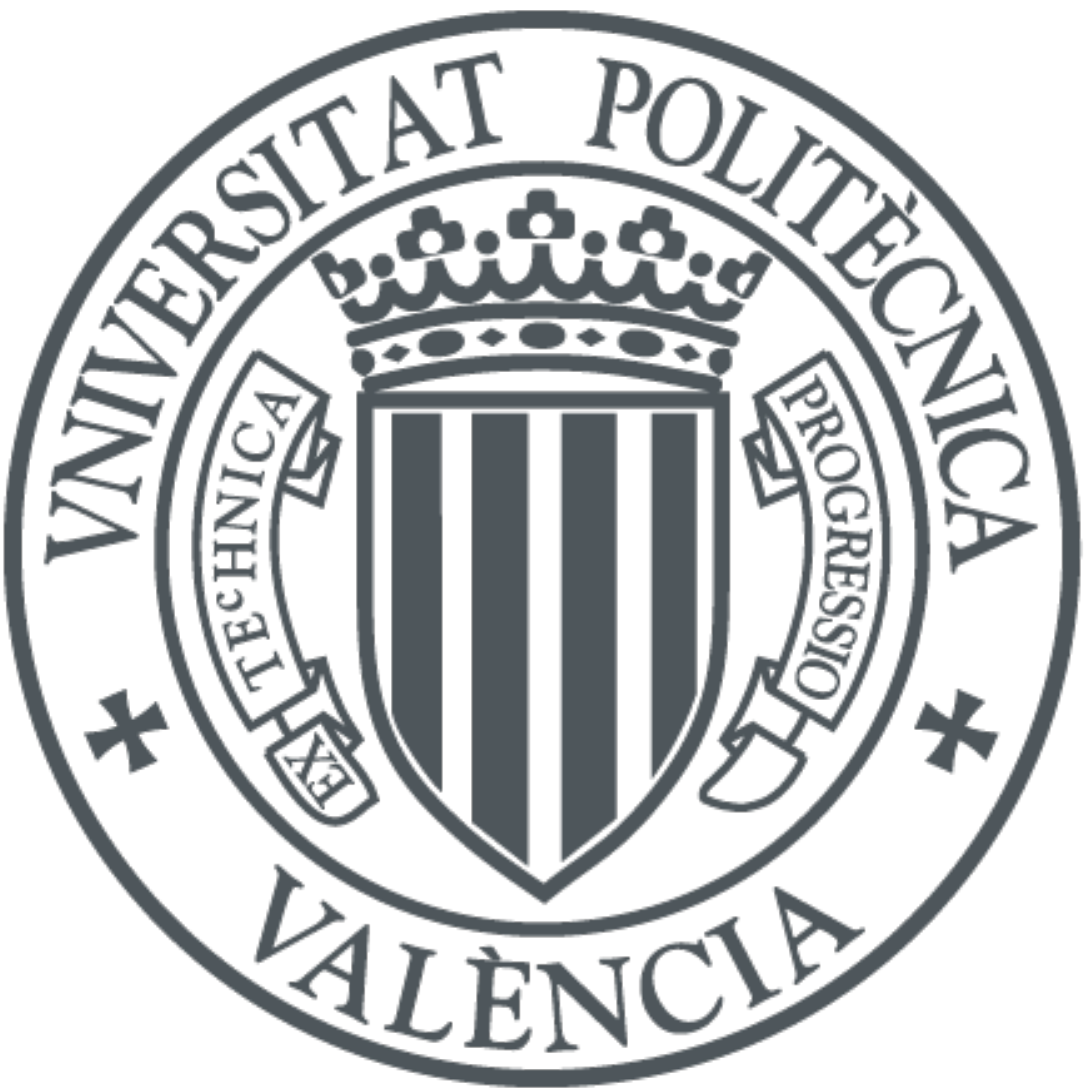

The final publication is available at

Copyright Elsevier

Additional Information 


\author{
Surface and Coatings Technology \\ Manuscript Draft
}

Manuscript Number: SURFCOAT-D-11-00448R1

Title: Microstructure and Photocatalytic Activity of Suspension Plasma Sprayed TiO2 Coatings on Steel and Glass Substrates

Article Type: Research Paper

Keywords: Photocatalytic coatings; Suspension plasma spraying; TiO2; Microstructure

Abstract: In this study, TiO2 coatings were deposited by suspension plasma spraying (SPS) from a commercial TiO2 nanoparticle suspension on two different substrates: a standard stainless steel and a Pyrex glass. Coatings were sprayed on both substrates with an F4-MB monocathode torch; a Triplex Pro tricathode torch was also used to spray coatings just on the stainless steel substrates. Spraying distance and cooling were varied.

The anatase content in the coatings, determined by XRD, ranged from 32 to $72 \mathrm{wt} \%$. A significant amount of anatase to rutile transformation was found to occur during cooling. Examination of the microstructure revealed that the coating microstructure was bimodal, involving a non-molten region consisting mainly of anatase nanoparticle agglomerates and a molten region. The glass substrate coatings displayed a segregated phase distribution, particularly when the surface to be coated was cooled. Photocatalytic activity was determined by a methylene blue test.

The experimental data fitted well to a first-order kinetic. All the coatings exhibited high photocatalytic activity in comparison with that of a commercial sol-gel coating. However, unlike much of the previous research, photocatalytic activity did not correlate with the anatase content determined by XRD. 


\section{Answers to reviewer}

2. Material and methods:

In the table 1 , the value of the suspension viscosity $<1000 \mathrm{mPas}$. It is that correct?

Table 1 contains the properties given in the technical bulletin of the suspension. The supplier

(EVONIK) does not give the exact value of the viscosity but only indicates that it is lower than $1000 \mathrm{mPa} \cdot \mathrm{s}$.

What was the suspension feedrate?

Suspension feedrate has been added to the manuscript (page 6).

Spray distance was varied during experiments, but values of spray distance could not be found in the text.

Spray distance has been included in table 2.

Moreover the substrate temperature during spraying with and without cooling, which presumely will influence the content of the anatase should be given.

As suggested, a graph showing the evolution of the substrate temperature during spraying with and without cooling has been added to the manuscript (figure 2).

Photocatalytic test:

What was the size of samples for MB test?

Photocatalytic tests were conducted by immersion of the complete coated samples $(25 \mathrm{~mm}$ diameter disks). This information has been included to the manuscript (page 8).

The solution of MB was stirred before the UV-VIs-measurements?

Yes. This information has been included to the manuscript (page 8).

\subsection{Composition of the crystalline phase:}

The authors made reference to literature, that considers the retention of anatase phase or anataserutile transformation. Unfortunately this section it is neither well organised nor logically presented (sometimes the literature it is false or inappropriated cited). In this manuscript, the reader can very hardly understand in which conditions anatase is retained or transformed into rutile phase (compared with f.e. with the article cited in Reference 29).

Moreover several sentences have not a really logical sense, i.e.: - at the end of page 8: "At similar cooling rate, increased particle melting led to a smaller quantity of preserved anatase in the coating, which confirms one of the main mechanisms reported in the literature on the origin of anatase in suspension plasma sprayed titania coatings $[12,20,29]$." Then the next sentence shows not direct link with the previous one. Also on the page 10: "Since the coatings sprayed with the F4-MB torch contained between 37 and $72 \mathrm{wt} \%$ anatase, it may be assumed that much of the phase transformation occurred after particle deposition. Most of this transformation was avoided, however, by efficient cooling of the samples."

In the meantime, the authors talked about efficient cooling rates or cooling of the samples, but no informations can be found about f.e. substrate temperature during spraying with or without cooling. This section needs revision.

The section "Composition of crystalline phases" has been rewritten taking into account the comments of the reviewer (pages 9-12).

In the Table 3, it is not very cleary explained what's means: "anatase to rutile tranformation (\%of overal all transformation) in flight and on substrate"

This information has been removed from table 3 (as a new table has been added, it is now referenced as table 4), which now gives the rutile content of the coatings and the crystalline phase composition of the feedstock and of in-flight particles. 


\subsection{Coating microstructure:}

In the sentence (end of page10): "Titanium and oxygen were the only elements identified by EDX in both molten and non-molten regions." Did the authors expect to find something else??

This sentence has been removed from the manuscript as it does not give any interesting information (page 12).

The authors affirmed that non-molten regions consisting of agglomerated nanoparticles, nonetheless differences in these regions (as shown in Figure 8) can be seen, i.e the sizes of nanoparticles are different when compare G2 (fig.8a) with S2 (fig. 8b) and ST2 (Fig.8c). Unfortunately the scale of $1 \mu \mathrm{m}$ in these micrographs is too big in order to estimated the size of very fine particles. Micrographs with appropriate scale are preferred.

Figure 8 has been modified (as new figures have been added it is now referenced as Figure 10) .

The sentence (begin of page 11): "The Raman curves show that the molten region located in the surface of sample G3 consisted entirely of anatase, while the XRD results for this sample showed that it contained 69\% anatase." it is in contradictory with the results of Figure 9 and the text previously written. Please revise.

This sentence effectively contained an error and has been modified (page 14).

The coatings sprayed on glass substrates showed a "segregated" microstructure. The authors suggested that this segregation results "from high cooling rates of these deposits" and especially for G3 and G4; nonetheless excepted for G5, all the coatings on glass substrates presented this kind of microstructure, either with or without cooling. Other(s) factor(s) should influence this specific microstructure.

It is true that the "segregated" microstructure may be influenced by other factors. However, such factors have not been identified at the moment and further investigation is necessary to fully explain these observations. Manuscript has been modified to clarify this point (page 13).

Figure 8: It is the magnification "x 120000" correct?

Yes, magnification is correct.

\subsection{Photocatalytic activity:}

The values of $k^{\prime}$ as shown in Tables 4,5 and Fig. 12 are expressed in " $\left(h^{\wedge}-1\right)^{*} 10^{\wedge} 2^{\prime \prime}$, but considering the diagramm shown in Fig.11, the $k^{\prime}$ should be expressed as " $\left(h^{\wedge}-1\right)^{*} 10^{\wedge}-2 "$. Please revise.(As orientation, please see the Fig. 5 in Reference 32).

The $\mathrm{k}^{\prime}$ are effectively between 0.12 and $0.17 \mathrm{~h}^{-1}$. However, following the nomenclature we

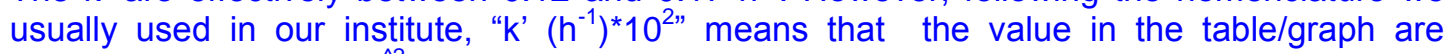
multiplicated by $100\left(10^{\wedge}\right)$. As this notation is not clear and leads to confusion, the units are now referred as $\left(10^{-2 *} \mathrm{~h}^{-1}\right)$ in tables 4 and 5 (as a new table has been added, they are now referenced as tables 5 and 6) and in figure 12 (as new figures have been added it is now referenced as Figure 14).

Please add literature/references where the coatings $\mathrm{Al}_{2} \mathrm{O}_{3}, \mathrm{Al}_{2} \mathrm{O}_{3}-13 \% \mathrm{TiO}_{2}, \mathrm{TiO}_{2}$ are described. Please insert information about the commercial $\mathrm{TiO}_{2}$ sol-gel coating. Information about the coating has been added to the manuscript (page 6).

In Reference 32: instead "20011" insert "2001"

The reference has been corrected (as a new reference has been added, it is now referenced as reference 33 ). 
Figure 1: Considering the XRD-difractogramm and the coating references, can be affirmed that the G1-coating contains the less anatase ratio and $\mathrm{S} 1$-coating the highest ratio - but these contradict the anatase content (wt\%) presented in Table 3 or in Fig2. Please revise.

Effectively, the references in the graph were interchanged. Figure 1 has been modified (as new figures have been added it is now referenced as Figure 3).

Figure 12: Which coatings (sample numbers) is presented in this graph?

Figure 12 has been modified to include sample references (as new figures have been added it is now referenced as Figure 14). 


\section{Highlights:}

1. $\mathrm{TiO}_{2}$ coatings were deposited by SPS on stainless steel and Pyrex glass

2. Large amounts of anatase were obtained in all coatings

3. A bimodal microstructure was observed, anatase is mainly found in nonmolten areas

4. Coatings present high photocatalytic activity compared to commercial sol-gel layer 


\section{Microstructure and Photocatalytic Activity of Suspension Plasma Sprayed $\mathrm{TiO}_{2}$ Coatings on Steel and Glass Substrates}

E. Bannier ${ }^{1 *}$, G. Darut ${ }^{2}$, E. Sánchez ${ }^{1}$, A. Denoirjean ${ }^{2}$, M.C. Bordes ${ }^{1}$, M.D. Salvador ${ }^{3}$, E. Rayón ${ }^{3}$, H. Ageorges ${ }^{2}$

${ }^{1}$ Instituto de Tecnología Cerámica - Asociación de Investigación de las Industrias Cerámicas. Universitat Jaume I. Av. Vicent Sos Baynat s/n, 12006 Castellón, Spain

${ }^{2}$ SPCTS, UMR CNRS 6638. Université de Limoges. Faculté des Sciences et Techniques, 123 avenue Albert Thomas, 87060 Limoges, France

${ }^{3}$ Universidad Politécnica de Valencia. Instituto de Tecnología de Materiales. Camino de Vera s/n, 46022 Valencia, Spain.

$\begin{array}{cc}* \text { corresponding author: } & \text { phone } \\ \operatorname{fax} & (+34) 964642424 \\ (+34) 964342425\end{array}$

E-mail addresses of all authors:
E. Bannier*: emilie.bannier@itc.uji.es
G. Darut: $\quad$ geoffrey.darut@unilim.fr
E. Sánchez : enrique.sanchez@itc.uji.es
A. Denoirjean: alain.denoirjean@unilim.fr
M.C. Bordes : $\quad$ carmen.bordes@itc.uji.es
M.D. Salvador : dsalva@mcm.upv.es
E. Rayón: $\quad$ emraen@upvnet.upv.es
H. Ageorges: helene.ageorges@unilim.fr 


\begin{abstract}
In this study, $\mathrm{TiO}_{2}$ coatings were deposited by suspension plasma spraying (SPS) from a commercial $\mathrm{TiO}_{2}$ nanoparticle suspension on two different substrates: a standard stainless steel and a Pyrex glass. Coatings were sprayed on both substrates with an F4MB monocathode torch; a Triplex Pro tricathode torch was also used to spray coatings just on the stainless steel substrates. Spraying distance and cooling were varied.

The anatase content in the coatings, determined by XRD, ranged from 32 to $72 \mathrm{wt} \%$. A significant amount of anatase to rutile transformation was found to occur during cooling. Examination of the microstructure revealed that the coating microstructure was bimodal, involving a non-molten region consisting mainly of anatase nanoparticle agglomerates and a molten region. The glass substrate coatings displayed a segregated phase distribution, particularly when the surface to be coated was cooled. Photocatalytic activity was determined by a methylene blue test.

The experimental data fitted well to a first-order kinetic. All the coatings exhibited high photocatalytic activity in comparison with that of a commercial sol-gel coating. However, unlike much of the previous research, photocatalytic activity did not correlate with the anatase content determined by XRD.
\end{abstract}

Keywords: Photocatalytic coatings, suspension plasma spraying, $\mathrm{TiO}_{2}$, microstructure 


\section{Introduction}

Nanostructured coatings are drawing increased scientific attention because of their potential enhancement of coating properties [1]. In conventional plasma spraying, micrometre-sized feedstock powders are injected within the plasma flow with a cold (i.e. room temperature) carrier gas. The decrease in particle size and weight from micro to nanoparticles requires an increase in particle injection velocity in order to keep the momentum quantity constant. As a result, the gas carrier flow rate also needs be raised, leading to disruption of the plasma and to untreated particles. Generally, two possible approaches can be used to manufacture nanostructured coatings: i) agglomeration of nanometre-sized particles into micrometre-sized feedstock that can be injected conventionally using a carrier gas or ii) use of a carrier liquid (suspension plasma spraying, SPS) instead of a carrier gas. SPS differs significantly from conventional atmospheric plasma spraying since the suspension is fragmented into droplets and the liquid phase vaporised before the solid feedstock is processed, leading to different operating parameters and different thermal histories during spraying. The process has undergone extensive development, yielding nanostructured SOFC functional layers $[2,3]$, thermal barrier coatings [4,5], wear resistant coatings [6], and photocatalytic layers [7]. Coatings with enhanced properties, in comparison with those of coatings obtained from conventional dry powders, have been reported [8]

Heterogeneous photocatalysis is a process that enables complete degradation of pollutants in water and air. Titanium dioxide $\left(\mathrm{TiO}_{2}\right)$ is, among semiconductors, the most widely used photocatalyst owing to its stability, non-toxicity, and relatively low cost.

Intense research in recent years has shown that thermal spray techniques, especially atmospheric plasma spraying (APS) and high velocity oxy-fuel spraying (HVOF), can 
be used to produce $\mathrm{TiO}_{2}$ coatings with effective photocatalytic activity $[9,10]$. This, together with the inherent advantage of feeding nanoparticle suspensions instead of nanostructured powders into the plasma torch, as set out above, has further raised interest in the preparation of photocatalytic $\mathrm{TiO}_{2}$ coatings by SPS $[8,11]$.

A key issue throughout all this research has been the preservation of the largest possible quantity of anatase phase in the coating, because of the superior photocatalytical performance of anatase compared to that of rutile. In fact, numerous papers have demonstrated the need to achieve a minimum anatase content in the coating, correlating anatase content with photocatalytic activity [12-14]. However, controversy persists with regard to the factors that control $\mathrm{TiO}_{2}$ phase (anatase versus rutile) distribution in the final layers. A mixture of anatase and rutile is always encountered, regardless of the nature and composition of the feedstock, while anatase and rutile content can vary widely [15-17].

Toma et al. [18] recently showed that titania coatings obtained by SPS of aqueous suspensions led to better photocatalytic layers, stating that a minimum threshold of 1520 vol.\% anatase was needed to obtain significant pollutant degradation. A subsequent paper [19] reported that when the anatase ratio exceeded a maximum threshold of 65 vol. \%, the anatase content contributed less to photocatalysis. Other factors could play a role such as those related to the adsorbed species on the coating surface $\overline{\bar{\alpha}}_{\overline{\mathbf{Z}}}[20]$.

Using submicrometric rutile suspensions, Kozerski et al. [21] recently showed that the photocatalytic performance of the titania deposits did not correlate with the anatase content, while coatings principally containing rutile were also photocatalytically active. That paper also noted the need for further research in order to clarify the relationship between process variables and coating microstructure in regard to photocatalytic activity. 
The present study was undertaken to prepare photocatalytic $\mathrm{TiO}_{2}$ coatings from aqueous nanoparticle suspensions by SPS. The impact of certain key plasma spraying conditions (such as spraying distance and cooling) on coating microstructure, phase distribution, and photocatalytic activity was studied. Standard stainless steel and Pyrex glass were used as substrates, the latter being tested in view of the growing interest in photocatalytic glass-supported coatings for wastewater treatment.

\section{Materials and methods}

\subsection{Materials}

All layers were deposited from a commercial suspension of $\mathrm{TiO}_{2}$ nanoparticles (AERODISP 740X, Evonik Degussa GmbH, Germany). The main suspension characteristics, as given by the supplier, are listed in Table 1.

TEM observations (H7100, Hitachi, Japan) of the nanoparticles in this suspension confirmed their nanometre size $(20-30 \mathrm{~nm})$. XRD analysis (D8 Advance, Bruker) indicated that they contained $90 \mathrm{wt} \%$ anatase and $10 \mathrm{wt} \%$ rutile.

Stainless steel (AISI 304 grade) and Pyrex glass were used as substrates $(25 \mathrm{~mm}$ diameter disks). The metal substrates were polished up to $\mathrm{SiC} 4000$ and both types of samples were cleaned with ethanol before coating deposition.

\subsection{Coating deposition}

Coatings were deposited using two different plasma torches: an F4-MB monocathode torch (Sulzer Metco, Wolhen Switzerland) with a $6 \mathrm{~mm}$ internal diameter anode was used to coat both stainless steel and glass substrates, while a Triplex Pro tricathode torch (Sulzer Metco, Wolhen Switzerland) with a $6.5 \mathrm{~mm}$ diameter segmented anode was used to coat only steel substrates. The substrates were pre-heated (between $200{ }^{\circ} \mathrm{C}$ and $300^{\circ} \mathrm{C}$ ) to enhance coating adhesion. 
As can be observed in Figure 1, samples were mounted on a rotating device and up to 6 samples were coated simultaneously. The suspensions were injected through a calibrated diaphragm of $150 \mu \mathrm{m}$ average diameter. Suspension momentum density upon penetration in the plasma flow was controlled by adjusting the pressure in the suspension containers. The characteristics of the suspension feeding system have been described elsewhere [22]. For all coatings suspension feedrate was $23 \mathrm{ml} \cdot \mathrm{min}^{-1}(28.2$ $\left.g \cdot \min ^{-1}\right)$.

The main spraying parameters used for each sample, as well as the sample references, are given in Table 2. All coatings were sprayed with a similar plasma mass enthalpy. The effects of both spraying distance and cooling were studied. Cooling was performed by spraying water $\left(8 \mathrm{ml} \cdot \mathrm{s}^{-1}\right)$ with compressed air (1 bar) on the surface to be coated, throughout the process. During deposition, the samples temperature was measured using a pyrometer. As a consequence of the holder geometry (Figure 1), the value measured using the pyrometer depends on both samples and holder temperatures. As holder and steel substrates display similar thermal conductivity, the temperature measured should be closed to the real sample temperature. However, in the case of glass samples, the temperature could not be determined accurately as a consequence of the important thermal conductivity differences existing between glass substrate and metallic holder. For comparation purposes, a commercial photocatalytic $\mathrm{TiO}_{2}$ sol-gel coating and three APS coatings were also deposited. The commercial sol-gel layer was obtained by spraying two suspensions on the substrate: a colloidal primer suspension (X-clean PK $3033 \mathrm{P}$, Nano-X GmbH, Germany) and a $\mathrm{TiO}_{2}$ nanosuspension (X-clean PK $3033 \mathrm{~F}$, Nano-X GmbH, Germany). After deposition the samples were thermally treated at 400 ${ }^{\circ} \mathrm{C}$. The main spraying parameters used to deposit the APS coatings are given in Table 
3. A complete characterization of the $\mathrm{Al}_{2} \mathrm{O}_{3}-\mathrm{TiO}_{2}$ nanostructured coatings have been published elsewhere [23].

\subsection{Determination of phase composition}

The nanoparticles present in the suspension feed and the resulting coatings were tested by X-ray diffraction (XRD) analysis, in order to determine their crystalline phase compositions. Anatase content was quantified using the Rietveld method.

The XRD diffractograms were obtained using a Bruker Theta-Theta model D8 Advance diffractometer with $\mathrm{CuK} \alpha$ radiation $(\lambda=1.54183 \AA)$. The generator settings were $45 \mathrm{kV}$ and $30 \mathrm{~mA}$. The XRD data were collected in a $2 \theta$ range of $5-90^{\circ}$ with a step width of $0.015^{\circ}$ and a counting time of $1.2 \mathrm{~s} / \mathrm{step}$. A VÅNEC- 1 detector was used.

In the case of the feeding nanoparticles, powder samples were prepared by drying the suspension feed and milling the resulting material in a pneumatic tungsten carbide ring mill to obtain agglomerates size below 40 microns [24]. The milled powder was subsequently backfilled into an appropriate specimen holder.

A quantitative phase analysis was conducted $[25,26]$ and the collected data were used in a Rietveld refinement [27,28]. The 4.2 version of the DIFFRACplus TOPAS Rietveld analysis program was used in this study, assuming a pseudo-Voight function to describe peak shapes. The refinement protocol included the background, scale factors, and instrument, as well as the sample lattice, profile, and texture parameters. The basic approach consists, first, of identifying all the crystalline phases present in the sample and then inputting the corresponding basic structural data. Finally, computer modelling is used to find the best fit to experimental patterns. An internal standard (fluorite) with a known concentration was introduced to analyse the powder samples. Rwp (R-weighted 
pattern) and GOF (goodness-of-fit) parameters were calculated in order to evaluate the accuracy of results.

\subsection{Observation of microstructure}

Coating microstructure was investigated by scanning electron microscopy (SEM) using an FEI Quanta 200F field-emission gun-SEM, connected to an energy-dispersive X-ray microanalysis (EDX) instrument. SEM observations were performed on polished crosssections of the different samples.

A HORIBA Jobin Yvon Raman spectrometer configured at $514.5 \mathrm{~nm}$ emission was used to characterise some coated sample cross-sections. The localisation of the analysis spot of the argon-ion laser was driven by an optical microscope.

\subsection{Characterisation of photocatalytic activity}

The photocatalytic activity of the coatings was ascertained by studying the decomposition of methylene blue (MB) in aqueous solution. The variation of the $\mathrm{MB}$ concentration in a $5 \mathrm{ppm} \mathrm{MB}$ solution in contact with the photocatalytic coating under UV radiation was determined. Irradiation was performed in a chamber using a UV-lamp $(\lambda=370 \mathrm{~nm})$ with an intensity of $2.5 \mathrm{~mW} / \mathrm{cm}^{2}$. The coated samples $(25 \mathrm{~mm}$ diameter disks) were immersed in a glass beaker containing $25 \mathrm{ml}$ of a 5 ppm MB solution. MB solution absorbance was measured at $664 \mathrm{~nm}$ wavelength, which is the maximum absorption peak of MB, using a UV-visible spectrometer. In order to allow the MB to be adsorbed on to the $\mathrm{TiO}_{2}$ surface, the test pieces were kept in contact with the solution for 30 minutes in the dark prior to irradiation, after which the MB concentration was determined. In the experimental procedure, the samples were continuously irradiated, a $6 \mathrm{ml}$ volume being withdrawn after $1,2,3,5,7$, and $11 \mathrm{~h}$ to measure, the concentration. The solution was stirred before each sampling and the withdrawn test liquid was 
returned to the solution after measurement. A blank sample with no coating was tested to evaluate the influence of UV radiation on the decrease in MB concentration by photolysis.

\section{Results and discussion}

\subsection{Sample temperature during deposition}

Figure 2 gives the evolution of the temperature during spraying for samples S1, S3 and S4. First, substrates were heated using the plasma torch. When the temperature reaches about $300{ }^{\circ} \mathrm{C}$, the aqueous suspension was introduced leading to a significant drop in both plasma and samples temperatures. Cooling was also turned on at the end of the pre-heating period.

It can be observed that sample temperature is only slightly dependent on the spraying distance, whereas cooling leads to significantly lower temperature values during deposition.

\subsection{Composition of the crystalline phases}

\subsubsection{Anatase content}

XRD analysis along with Rietveld refinement revealed that all deposited coatings consisted of mixtures of rutile and anatase (Figure 3). It was found that the coatings contained between 32 and 72 wt\% anatase (Table 4). Moreover, suspension feed was sprayed with an F4-MB torch and the in-flight particles were collected in water instead of being allowed to impinge upon the substrate. The resulting powder was dried and analysed by XRD, showing an anatase content of 74 wt $\%$ whereas the feedstock initially contains $90 \mathrm{wt} \%$ anatase (Table 4, Figure 4).

From the phase composition analysis, the following results may be highligthed: 
- The anatase content was lower in the coatings than in the initial suspension, which indicates phase transformation of titanium dioxide during deposition.

- In-flight particles display lower rutile content than the coatings, as a consequence it may be assumed that much of the phase transformation occurred after particle deposition.

- Cooling leaded to notably higher anatase content (Figure 5).

- Spraying distance had a major effect on coating crystalline phase composition: anatase content increased significantly with spraying distance (Figure 6).

- The type of plasma torch affected the crystalline phase composition. At similar spraying distance and plasma enthalpy, the layers deposited with the tricathode gun displayed lower anatase content (Figure 6).

- Substrate nature had no notable influence on the phase composition (Figure 6).

\subsubsection{Anatase to rutile phase transformation mechanisms}

In order to obtain coatings with large amount of anatase, it is generally considered that the plasma plume temperature must be low enough to avoid an excessive particles heating, which will promote the phase transformation [29]. Indeed, it is commonly accepted that transformation from anatase to rutile occurs at a temperature of about 900 K [30].

Actually, the anatase found in the coatings may come from unmolten particles, which retained the initial powder crystalline structure [20], or from the nucleation of anatase from melted particles [31], which explained that some anatase is found even when the suspension feedstock is purely rutile [16, 21]. After impingement of the molten particles onto the substrate, the anatase to rutile transformation is promoted by the reheating of previously deposited layers by successive passes of the torch [32]. 
In fact, from a thermodynamics point of view the recrystallisation of anatase from the liquid phase is more favourable, due to its lower surface energy compare to rutile [30]. Then, anatase will transform to rutile, which displays a lower Gibbs free-energy. However, the anatase to rutile transformation is reconstructive, which means that it is time dependent [30]. As a consequence, a higher cooling rate of the coatings after deposition should reduce the formation of rutile, which is confirmed by the results shown in Table 4: the coatings obtained using water cooling (samples G3, G4, and S4) yielded the highest anatase content.

It was also found that using the tricathode torch leads to lower anatase content (Table 4). In fact, the tricathode torch led to more efficient heat transfer from the plasma to the particles and, though, to enhanced particle heating inside the plasma jet. As the particles reach higher temperature, the driving force for anatase to rutile transformation is increased leading to higher rutile content in the coating.

Several authors have reported that spraying distance has a significant effect on anatase content $[16,31]$. The results obtained in this study confirmed that the quantity of anatase to rutile transformation decreased when the plasma torch was moved farther from the sample (Table 4). As the temperature of the samples is not significantly influenced by the spraying distance (Figure 2), it may be assumed that the differences found in the crystalline structure are not mainly due to changes in the cooling rate. Yet several hypothesis may explain these results. First, spraying distance may influence the particles velocity, leading to differences in splat flattening. Actually, Colmenares et al. have shown that at higher impact velocity, the anatase content increased due to an enhancement in splat flattening and, though, to higher splat solidification rate [32]. As a result, the amount of anatase to rutile transformation is reduced. Furthermore, Jaworski et al. have reported that, as spraying distance augments, the number of particles which 
resolidify before impact onto the substrate is increased [31]. The entrapment of such particles inside the coatings might promote the formation of a higher amount of rutile [32]. Finally, as the spraying distance is increased, the flight time in the plasma jet is longer, which give more time for the anatase to rutile transformation to occur before impact on the substrate.

\subsection{Coating microstructure}

Coating microstructure was observed by SEM (Figures 7 to 10). All coatings were dense and the porosity measurable by optical or electronic microscopy was negligible. In general, the coatings consisted of a bimodal microstructure characterised by the presence of completely fused (light-coloured) regions and of non-molten (darkcoloured) regions consisting of agglomerated nanoparticles, as may be observed in the high-magnification micrographs (Figure 10). Such microstructures, characterised by a distribution of non-melted and melted regions, have been previously reported in suspension plasma sprayed coatings obtained from titania and other materials such as alumina [18]. The microstructure develops because, when the suspension is injected into the plasma, the drops generated by the continuous jet break-up are accelerated in the plasma and disintegrate into smaller ones. At the same time, the water still present in the droplets boils and evaporates: the resulting particles may thus be heated, partly melted, or melted, yielding the end coating. The resulting microstructure largely depends on the characteristics of the suspension feed and the plasma feed system [21,29].

\section{Titanimm and oxygen were the only elements identified by EDX in both molten and}

Anatase content determined by XRD seems to increase when the total area of non-molten regions augments. As a consequence, anatase phase is expected to occur mostly in the non-molten areas. However, part of the anatase may have 
crystallised from liquid droplets and may, therefore, belong to the molten areas, as set out above [16,32].

In the case of the steel substrate coatings, molten and non-molten areas were quite intimately mixed. In contrast, segregation was observed in the glass substrate coatings, which led to an increase in the non-molten areas from the deposit-substrate interface upward to the outer deposit surface. This effect was particularly notable on cooled glass substrate (coatings G3 and G4 in Figure 8), suggesting that a higher cooling rate promotes the segregation. However, as samples G1 and G2 presented the same type of microstructure, cooling is not the only factor of influence. Further investigation will be needed in order to fully understand the origin of the segregation.

Finally, cooling usually resulted in degradation of the microstructure, leading to poorer adhesion and the presence of many defects, such as cracks. Such problems presumably stemmed from the presence of a water film on the sample surface, which hindered particle deposition. As a result of differences in the holding systems used for the glass and steel substrates, the water film was much thicker in the case of the steel substrates, which probably explains the poor quality of coating S4 (Figure 7d). Finally, significant differences were noted in coating thickness (Table 4). In particular, steel substrate coating thickness increased when the spraying distance decreased and/or when the tricathode torch was used, probably owing to higher spraying efficiency.

In order to properly identify whether the anatase phase was particularly associated with the non-melted areas, a Raman microscopy analysis was performed on selected coating samples. The technique has already been successfully used in discerning anatase and rutile phases in the microstructure of titania coatings [16]. The analysis was carried out on the G3 sample, which displayed clearly segregated non-molten and molten areas, owing to water cooling of the glass substrate surface to be coated. The microstructure of 
this coating, together with the spot size of the Raman laser on each (molten and nonmolten) region, is depicted in Figure 11. The Raman curves show that the non-molten region located in the surface of sample G3 consisted entirely of anatase, while the XRD results for this sample showed that it contained $69 \%$ anatase. It may be noted that the XRD technique, which is carried out at the surface, penetrates several tens of micrometres (approximately $20 \mu \mathrm{m}$ for $\mathrm{TiO}_{2}$ coatings) into the coating layer, whereas Raman spectroscopy focuses on spots a few micrometres in size in the sample crosssection. As a result, the findings cannot be compared.

\subsection{Photocatalytic activity}

Coating photocatalytic activity was determined by measuring the degradation of methylene blue (MB) dye in an aqueous solution. The variation in MB with irradiation time for the solutions in contact with sample G1 and with a blank substrate (B) are shown in Figure 12.

Clear differences were found in the solution concentrations at each irradiation time. A pronounced decrease in concentration was observed for the coated sample, whereas the blank substrate exhibited no significant degradation after the UV irradiation. This finding verified the photocatalytic activity of the test coating. Similar results were obtained for all coatings sprayed on to both glass and steel substrates, independently of the type of plasma torch used. In addition, MB initial adsorption at the end of soaking time in the dark was quite small in every case, confirming the low porosity found in the coatings.

The variation in $\mathrm{MB}$ concentration with time may be represented using the LangmuirHinshelwood first-order kinetic equation, which is applied to low concentrations [33]:

$$
-\frac{d C}{d t}=k^{\prime} C
$$


After integration, Equation 1 gives:

$$
-\ln \frac{C}{C_{0}}=k^{\prime} t
$$

where $\mathrm{C}$ is the $\mathrm{MB}$ concentration $(\mathrm{ppm}), \mathrm{C}_{0}$ is the $\mathrm{MB}$ initial concentration after residence time in darkness ( $\mathrm{ppm}), \mathrm{t}$ is the irradiation time $(\mathrm{h})$, and $\mathrm{k}^{\prime}$ is the constant of photocatalytic activity $\left(\mathrm{h}^{-1}\right)$. The plot of $\ln \left(\mathrm{C}_{0} / \mathrm{C}\right)$ versus time yields a straight line whose slope corresponds to the rate constant $k^{\prime}$. Figure 13 shows the variation of $\ln \left(\mathrm{C}_{0} / \mathrm{C}\right)$ with irradiation time for sample $\mathrm{G} 1$. A higher value of $\mathrm{k}^{\prime}$ means a faster degradation rate of the organic molecule.

The rate constants and correlation coefficients $\left(\mathrm{r}^{2}\right)$ determined from the kinetic model (Eq. 2) for all coatings are presented in Table 5. In every $y_{\Lambda}$ case, the correlation coefficients were higher than 0.988 , indicating a reasonably good fit of the kinetic model to the experimental data. A similar fit was found by Toma et al. [18] with suspension plasma sprayed titania coatings, though the rate constants were quite different owing to the different test conditions and chemical reagent used.

For comparison purposes, the $\mathrm{k}^{\prime}$ values were determined in the case of a commercial photocatalytic $\mathrm{TiO}_{2}$ sol-gel coating and of 3 atmospheric plasma sprayed coatings enderen $\left(\mathrm{Al}_{2} \mathrm{O}_{3}, \mathrm{Al}_{2} \mathrm{O}_{3}-13\right.$ wt $\% \mathrm{TiO}_{2}$ and $\left.\mathrm{TiO}_{2}\right)$.

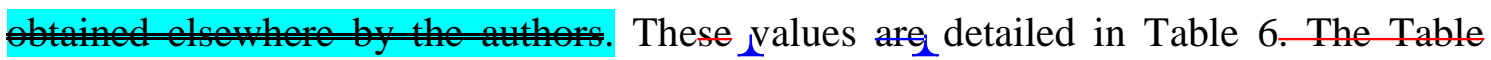
shows that the photocatalytic activity of the suspension plasma sprayed coatings prepared in this study was almost twice that of the titania coating obtained from the dry powder, and even much higher than that of the commercial sol-gel coating. These results confirm the good photocatalytic performance of the suspension plasma sprayed $\mathrm{TiO}_{2}$ coatings. 
The value of $\mathrm{k}^{\prime}$ versus anatase content of all the test coatings is plotted in Figure 14. Unlike most previous research, no correlation was observed between both variables. However, this finding was to some extent expected since, as indicated above, the amount of anatase phase determined by XRD did not suitably represent the amount of anatase phase at the coating surface. The lack of linear correlation between anatase content and photocatalytic activity was reported by Toma et al. [19]. These authors demonstrated the need to consider other factors, such as coating surface hydroxylation, the amount and binding strength of the bonded water, or other adsorbed species on the coating surface, in order to explain the photocatalytic activity of suspension plasma sprayed coatings with high anatase content. Kozerski et al. [21] recently confirmed this lack of correlation and demonstrated the photocatalytic activity of suspension plasma sprayed titania coatings that consisted mainly of rutile. These results all underline the role of the surface in photocatalytic activity and the need, therefore, to physically and chemically analyse the coating surface and the interaction between the surface and the environment. Different coatings are currently being analysed by IR and XPS with a view to better understanding this issue.

\section{Conclusions}

$\mathrm{TiO}_{2}$ coatings were prepared by suspension plasma spraying from a commercial $\mathrm{TiO}_{2}$ nanoparticle suspension using two different substrates (a standard stainless steel and a Pyrex glass), modifying spraying distance, cooling, and type of torch.

A large amount of anatase was obtained, ranging from 32 to $72 \mathrm{wt} \%$. The nature of the substrate was found to have no notable influence on anatase content. In contrast, the type of plasma torch significantly affected the resulting amount of anatase. Spraying distance, as well as cooling, had a major effect on coating crystalline phase 
composition: anatase content increased significantly with both cooling and spraying distance.

In general, the resulting coatings displayed a bimodal microstructure characterised by the presence of completely fused regions, as well as of non-molten regions comprising agglomerated anatase nanoparticles. The anatase phase was mostly found in the nonmolten areas. In the coatings sprayed on steel substrates, the molten and non-molten areas were quite intimately mixed, whereas segregation was observed in the case of the glass substrate coatings, particularly when the glass surface to be coated was cooled.

Coating photocatalytic activity was determined by measuring the degradation of methylene blue $(\mathrm{MB})$ dye in an aqueous solution. The studied first-order kinetic model exhibited a reasonably good fit to the experimental data for all test coatings. The values of the kinetic constant for these coatings were, in every case, much higher than that for a commercial sol-gel coating. However, unlike most previous research, photocatalytic activity was not observed to correlate with the anatase content determined by XRD.

\section{Acknowledgements}

This work has been supported by the Spanish Ministry of Science and Education (MAT2009-14144-C03-01), by the Spanish Ministry of Science and Innovation (PID600200-2009-5) and by the European Commission in the frame of the Interreg IV B Sudoe programme (Eliare: SOE1/P1/F169). 


\section{References}

[1] M. Gell, Mater. Sci. Eng. A 204 (1995) 246-251

[2] P. Fauchais, R. Etchard-Salas, C. Delbos, M. Tognonvi, V. Rat, J.F. Coudert, T. Chartier, J. phys D: appl. Phys. 40 (2007) 2394-2406

[3] D. Waldbilig, O. Kesier, Z. Tang, A. Burgess, in: N.R. Marple et al. (Eds.), Thermal Spray: Global Coating Solutions, ASM International, Materials park [OH], 2007, pp. 677-682

[4] A. D. Jadhav, N.P. Padture, Surf. Coat. Technol. 202 (2008) 4976-4979

[5] J. Oberste-Berghaus, J.G. Legoux, C. Moreau, J. Therm. Spray. Technol. 17 (2008) 91-104

[6] J. Oberste-Berghaus, B.R. Marple, C. Moreau, J. Therm. Spray. Technol. 15 (2006) 676-681

[7] L. Pawlowski, Surf. Coat. Technol. 202 (2008) 4318-4328

[8] L. Pawlowski, Surf. Coat. Technol. 203 (2009) 2807-1829

[9] Zeng Yi, Juntao Li, Wu Wei, Jianrong Wang, Soo Wohn Lee, Ceram. Int. 34 (2008) 351-357

[10] G. Bolelli, V. Cannillo, R. Gadow, A. Killinger, L. Lusvarghi, J. Rauch, Surf. Coat. Technol. 203 (2009) 1722-1732

[11] F.L. Toma, G. Bertrans, D. Klein, C. Meunier, S. Begin, S., J. Nanomater. (2008) http://www.hindawi.com/journals/jnm/2008/384171.html [Visited: 2010-12-02]

[12] F.L. Toma, D. Sokolov, G. Bertrand, D. Klein, C. Coddet, C. Meunier, J. Therm. Spray Technol. 15 (2006) 576-581

[13] X.Y. Wang, Z. Liu, H. Liao, D. Klein, C. Coddet, Thin Solid Films 451-452 (2004) $37-42$

[14] L. Toma, N. Keller, G. Bertrand, D. Klein, C. Coddet, Int. J. Photoener. 5 (2003) $141-145$

[15] J. Colmenares-Angulo, S. Zhao, C. Young, A. Orlov, Suf. Coat. Technol. 204 (2009) 423-427

[16] H. Podlesak, L. Pawlowski, J. Laureyns, T. Jaworski, T. Lampke, Surf. Coat. Technol. 202 (2008) 3723-3731

[17] E. Bemporad, G. Bolelli, V. Cannillo, D. de Felicis, R. Gadow, A. Killinger, L. Lusvarghi, J. Rauch, M. Sebastiani, Surf. Coat. Technol. 204 (2010) 3902-3910 
[18] F.L. Toma, L.M. Berger, C.C. Stahr, T. Naumann, S. Langner, J. Therm. Spray Technol. 19 (2010) 262-274

[19] F.L. Toma, L.M. Berger, D. Jacquet, D. Wicky, I. Villaluenga, Y.R. de Miguel, J.S. Lindeløv, Surf. Coat. Technol. 203 (2008) 2150-2156

[20] F.L. Toma, G. Bertrand, S. Begin, C. Meunier, O. Barres, D. Klein, C. Coddet, App. Catal. B: Environ. 68 (2006) 74-84

[21] S. Kozerski, F.L. Toma, L. Pawlowski, B. Leupolt, L. Latka, L.M. Berger, Surf. Coat. Technol. 205 (4) (2010) 980-986

[22] R. Etchart-Salas, V. Rat, J. F. Coudert, P. Fauchais, N. Caron, K. Wittmann Teneze, S. Alexandre, J. Therm. Spray. Technol. 16 (5-6) (2007) 857-865

[23] E. Sánchez, E. Bannier, M. Vicent, A. Moreno, M.D. Salvador, V. Bonache, E. Klyatskina, A.R. Boccaccini, Int. J. Appl. Ceram. Technol. (2010), DOI: $10.1111 / \mathrm{j} .1744-7402.2010 .02547 . \mathrm{x}$

[24] E. Burkhe, R. Jenkins, D.K. Smith (Eds.), A practical guide for the preparation of specimens for X-ray fluorescence and X-ray diffraction analysis. Wiley, New York, 1998, pp. 171-174

[25] A. L. Ortiz, F. Sánchez-Bajo, F.L. Cumbrera, F. Guiverteau, Mater. Lett. 49 (2001) $137-145$

[26] A. L. Ortiz, F. Sánchez-Bajo, N.P. Padture, F.L. Cumbrera, F. Guiverteau, J. Eur. Ceram. Soc. 21 (2001) 1237-1248.

[27] R. E. Young (Ed.), The Rietveld method. University press, Oxford. 1996.

[28] H. M. Rietveld, J. Appl. Crystal. 2 (1969) 65-71.

[29] F.L. Toma, G. Bertrand, D. Klein, C. Coddet, C. Meunier, J.Therm. Spray Technol. 15 (2006) 587-592

[30] D.A.H Hanaor, C.C. Sorrell, J. Mater. Sci. 46 (2011), 855-874

[31] R. Jaworski, L. Pawlowski, F. Roudet, S., Kozerski, A. le Maguer, J.Therm. Spray Technol. 17 (2008) 73-81.

[32] J.R. Colmenares-Angulo, V. Cannillo, L. Lusvarghi, A. Sola, S. Sampath, J. Mater. Sci. 44 (2009) 2276-2287

[33] A. Houas, H. Lachleb, M. Ksibi, E. Elaloui, C. Guillard, J. M. Herrmann, Applied Catalysis B: Environmental 31 (2001) 145-157 


\section{Tables}

Table I. Nanosuspension main characteristics (according to supplier information).

\begin{tabular}{|c|c|c|c|c|c|c|}
\hline Reference & Supplier & $\begin{array}{c}\mathbf{T i O}_{2} \text { content } \\
(\mathbf{w t} \%)\end{array}$ & $\mathbf{p H}$ & $\begin{array}{c}\text { Viscosity } \\
(\mathbf{m P a} \cdot \mathbf{s})\end{array}$ & $\begin{array}{c}\text { Mean aggregate } \\
\text { size }(\mathbf{n m})\end{array}$ & $\begin{array}{c}\text { Density at 20 }{ }^{\mathbf{}} \mathbf{C} \\
\left(\mathbf{g} / \mathbf{c m}^{\mathbf{3}}\right)\end{array}$ \\
\hline Aerodisp $740 \mathrm{X}$ & Evonik & 40 & $5.0-7.0$ & $<1000$ & $<100$ & 1.41 \\
\hline
\end{tabular}


Table II. Main spraying parameters and sample references.

\begin{tabular}{|c|c|c|c|c|c|c|c|c|c|c|}
\hline Sample & Substrate & Torch & $\begin{array}{c}\text { Nozzle } \\
(\mathbf{m m})\end{array}$ & $\begin{array}{c}\text { Ar } \\
(\mathbf{l} / \mathbf{m i n})\end{array}$ & $\begin{array}{c}\text { He } \\
(\mathbf{l} / \mathbf{m i n})\end{array}$ & $\begin{array}{c}\text { Arc } \\
\text { intensity } \\
(\mathbf{A})\end{array}$ & $\begin{array}{c}\text { Arc } \\
\text { tension } \\
(\mathbf{V})\end{array}$ & $\begin{array}{c}\text { Plasma } \\
\text { mass } \\
\text { enthalpy } \\
(\mathbf{M J} / \mathbf{k g})\end{array}$ & $\begin{array}{c}\text { Spray } \\
\text { distance } \\
(\mathbf{m m})\end{array}$ & Cooling \\
\hline G1 & glass & F4-MB & 6 & 50 & 10 & 400 & 38.8 & 5.7 & 60 & No \\
\hline G2 & glass & F4-MB & 6 & 50 & 10 & 400 & 38.5 & 5.7 & 40 & No \\
\hline G3 & glass & F4-MB & 6 & 50 & 10 & 400 & 39.3 & 5.8 & 40 & Yes \\
\hline G4 & glass & F4-MB & 6 & 50 & 10 & 400 & 38.8 & 5.8 & 50 & Yes \\
\hline G5 & glass & F4-MB & 6 & 50 & 10 & 400 & 38.8 & 5.7 & 50 & No \\
\hline S1 & steel & F4-MB & 6 & 50 & 10 & 400 & 38.8 & 5.4 & 40 & No \\
\hline S2 & steel & F4-MB & 6 & 50 & 10 & 400 & 38.3 & 5.6 & 60 & No \\
\hline S3 & steel & F4-MB & 6 & 50 & 10 & 400 & 38.6 & 5.5 & 50 & No \\
\hline S4 & steel & F4-MB & 6 & 50 & 10 & 400 & 38.3 & 5.6 & 50 & Yes \\
\hline ST1 & steel & Triplex & 6.5 & 60 & 0 & 200 & 80.4 & 5.8 & 60 & No \\
\hline ST2 & steel & Triplex & 6.5 & 60 & 0 & 200 & 80.4 & 5.8 & 40 & No \\
\hline
\end{tabular}


Table III. APS spraying parameters

\begin{tabular}{|c|c|c|c|c|c|c|c|c|c|}
\hline Coating & $\begin{array}{l}\text { Powder } \\
\text { reference }\end{array}$ & $\begin{array}{l}\text { Powder } \\
\text { supplier }\end{array}$ & Torch & $\begin{array}{c}\text { Nozzle } \\
(\mathbf{m m})\end{array}$ & $\underset{(1 / \text { min })}{A \mathbf{r}}$ & $\begin{array}{c}\text { He } \\
(\mathbf{l} / \mathbf{m i n})\end{array}$ & $\begin{array}{c}\mathbf{H}_{2} \\
(\mathbf{l} / \mathbf{m i n})\end{array}$ & $\begin{array}{c}\text { Arc } \\
\text { intensity } \\
\text { (A) } \\
\end{array}$ & $\begin{array}{c}\text { Spray } \\
\text { distance } \\
(\mathbf{m m})\end{array}$ \\
\hline $\begin{array}{c}\mathrm{APS}-\mathrm{Al}_{2} \mathrm{O}_{3} \\
\text { (conventional) }\end{array}$ & $\begin{array}{l}\text { METCO } \\
105 \text { SFP }\end{array}$ & $\begin{array}{c}\text { Sulzer } \\
\text { Metco, } \\
\text { Germany } \\
\end{array}$ & F4-MB & 6 & 35 & - & 12 & 600 & 120 \\
\hline $\begin{array}{c}\text { APS- }\left(\mathrm{Al}_{2} \mathrm{O}_{3^{-}}\right. \\
\left.13 \mathrm{wt} \% \mathrm{TiO}_{2}\right) \\
\text { (nanostructured) }\end{array}$ & $\begin{array}{c}\text { NANOX } \\
\text { S2613S }\end{array}$ & $\begin{array}{c}\text { Inframat } \\
\text { advanced } \\
\text { Materials, } \\
\text { USA }\end{array}$ & F4-MB & 6 & 35 & - & 12 & 600 & 120 \\
\hline $\begin{array}{c}\mathrm{APS}^{-\mathrm{TiO}_{2}} \\
\text { (nanostructured) }\end{array}$ & $\begin{array}{l}\text { NEOXID } \\
\text { T101 nano }\end{array}$ & $\begin{array}{l}\text { MilliDyn, } \\
\text { Finland }\end{array}$ & F4-MB & 6 & 40 & 20 & - & 600 & 120 \\
\hline
\end{tabular}


Table IV. Feedstock and coating characteristics.

\begin{tabular}{|c|c|c|c|c|c|}
\hline \multirow{2}{*}{ Sample } & \multirow{2}{*}{ Thickness } & Anatase & \multicolumn{2}{|c|}{ Rutile } & \multicolumn{2}{|c|}{ Rietveld refinement } \\
\cline { 4 - 6 } & $(\mu \mathrm{m})$ & $(\mathrm{wt} \%)$ & $(\mathrm{wt} \%)$ & Rwp & GOF \\
\hline $\begin{array}{c}\text { Suspension } \\
\text { feed }\end{array}$ & - & 90 & 10 & 9.30 & 1.55 \\
\hline $\begin{array}{c}\text { In-flight } \\
\text { particles }\end{array}$ & - & 74 & 26 & 9.98 & 1.78 \\
\hline G1 & 15 & 59 & 41 & 15.68 & 2.52 \\
\hline G2 & 29 & 38 & 62 & 11.18 & 1.82 \\
\hline G3 & 28 & 69 & 31 & 14.43 & 2.43 \\
\hline G4 & 15 & 72 & 28 & 16.83 & 2.75 \\
\hline G5 & 39 & 46 & 54 & 11.50 & 1.87 \\
\hline S1 & 45 & 37 & 63 & 10.61 & 1.73 \\
\hline S2 & 23 & 59 & 41 & 14.15 & 2.49 \\
\hline S3 & 32 & 46 & 54 & 10.70 & 1.70 \\
\hline S4 & 14 & 68 & 32 & 15.52 & 2.95 \\
\hline ST1 & 36 & 44 & 56 & 9.85 & 1.60 \\
\hline ST2 & 55 & 32 & 68 & 11.24 & 1.76 \\
\hline
\end{tabular}


Table V. Photocatalytic rate constants and correlation coefficients of the coatings.

\begin{tabular}{|c|c|c|}
\hline Sample & $\begin{array}{c}\text { Rate constant } \\
\left(\mathbf{1 0}^{-2} * \mathbf{h}^{-1}\right)\end{array}$ & $\mathbf{r}^{\mathbf{2}}$ \\
\hline G1 & 12.5 & 0.991 \\
\hline G2 & 13.2 & 0.989 \\
\hline G3 & 15.0 & 0.990 \\
\hline G4 & 11.8 & 0.998 \\
\hline G5 & 12.2 & 0.988 \\
\hline S1 & 15.0 & 0.992 \\
\hline S2 & 11.2 & 0.990 \\
\hline S3 & 13.7 & 0.992 \\
\hline S4 & 14.0 & 0.990 \\
\hline ST1 & 13.5 & 0.991 \\
\hline ST2 & 17.1 & 0.989 \\
\hline
\end{tabular}


Table VI. Photocatalytic rate constants of three APS coatings and one commercial solgel coating, obtained elsewhere by the authors.

\begin{tabular}{|c|c|}
\hline Sample & $\begin{array}{c}\text { Rate constant } \\
\left(\mathbf{1 0}^{-\mathbf{2}} * \mathbf{h}^{\mathbf{- 1}}\right)\end{array}$ \\
\hline $\mathrm{APS}-\mathrm{Al}_{2} \mathrm{O}_{3}$ & 0.5 \\
\hline APS-( $\left.\mathrm{Al}_{2} \mathrm{O}_{3}-13 \mathrm{wt} \% \mathrm{TiO}_{2}\right)$ & 2.4 \\
\hline $\mathrm{APS}-\mathrm{TiO}_{2}$ & 7.3 \\
\hline Commercial $\mathrm{TiO}_{2}$ sol-gel & 5.8 \\
\hline
\end{tabular}




\section{Figure captions}

Figure 1. Suspension plasma spraying equipment.

Figure 2. Evolution of the samples temperature during spraying.

Figure 3. XRD patterns of coatings G1, S1, and ST1. The peaks labelled A and R correspond, respectively, to anatase and rutile phases.

Figure 4. XRD patterns of the suspension feed nanoparticles (top) and of the in-flight particles collected in water (bottom). The peaks labelled A and R correspond, respectively, to anatase and rutile phases.

Figure 5. Effect of cooling on coating anatase content (glass substrate).

Figure 6. Effect of spraying distance on coating anatase content (glass and steel substrates, without cooling).

Figure 7. SEM micrographs of suspension plasma sprayed $\mathrm{TiO}_{2}$ coatings obtained on steel substrates with an F4-MB plasma gun: a) S1, b) S2, c) S3, and d) S4.

Figure 8. SEM micrographs of suspension plasma sprayed $\mathrm{TiO}_{2}$ coatings obtained on glass substrates with an F4-MB plasma gun: a) G1, b) G2, c) G3, d) G4, and e) G5.

Figure 9. SEM micrographs of suspension plasma sprayed $\mathrm{TiO}_{2}$ coatings obtained on steel substrates with a Triplex Pro torch: a) ST2 and b) ST1.

Figure 10. High-magnification SEM micrographs (x120000) of non-molten areas found in the coatings: a) G2, b) S2, and c) ST2.

Figure 11. Raman spectra results in the marked sites (R1 and R2 spots) of sample G3. A: Anatase and R: Rutile.

Figure 12. Variation of MB concentration with UV irradiation time for solutions in contact with the G1 coating and with a blank sample.

Figure 13. Variation of $\ln \left(\mathrm{C}_{0} / \mathrm{C}\right)$ with irradiation time for sample $\mathrm{G} 1$.

Figure 14. Effect of anatase content (wt \%) on coating photocatalytic activity 


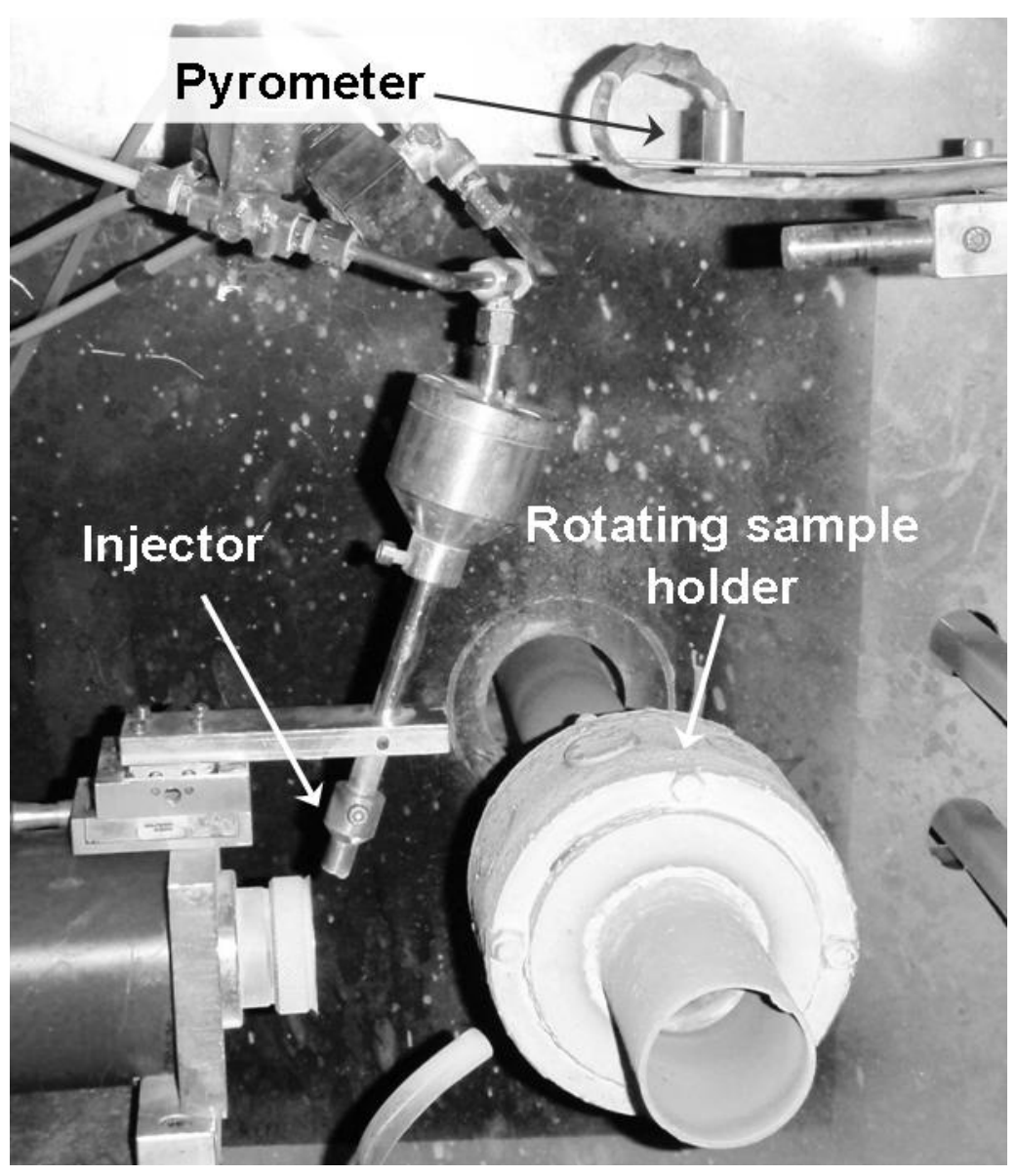

Figure 1 


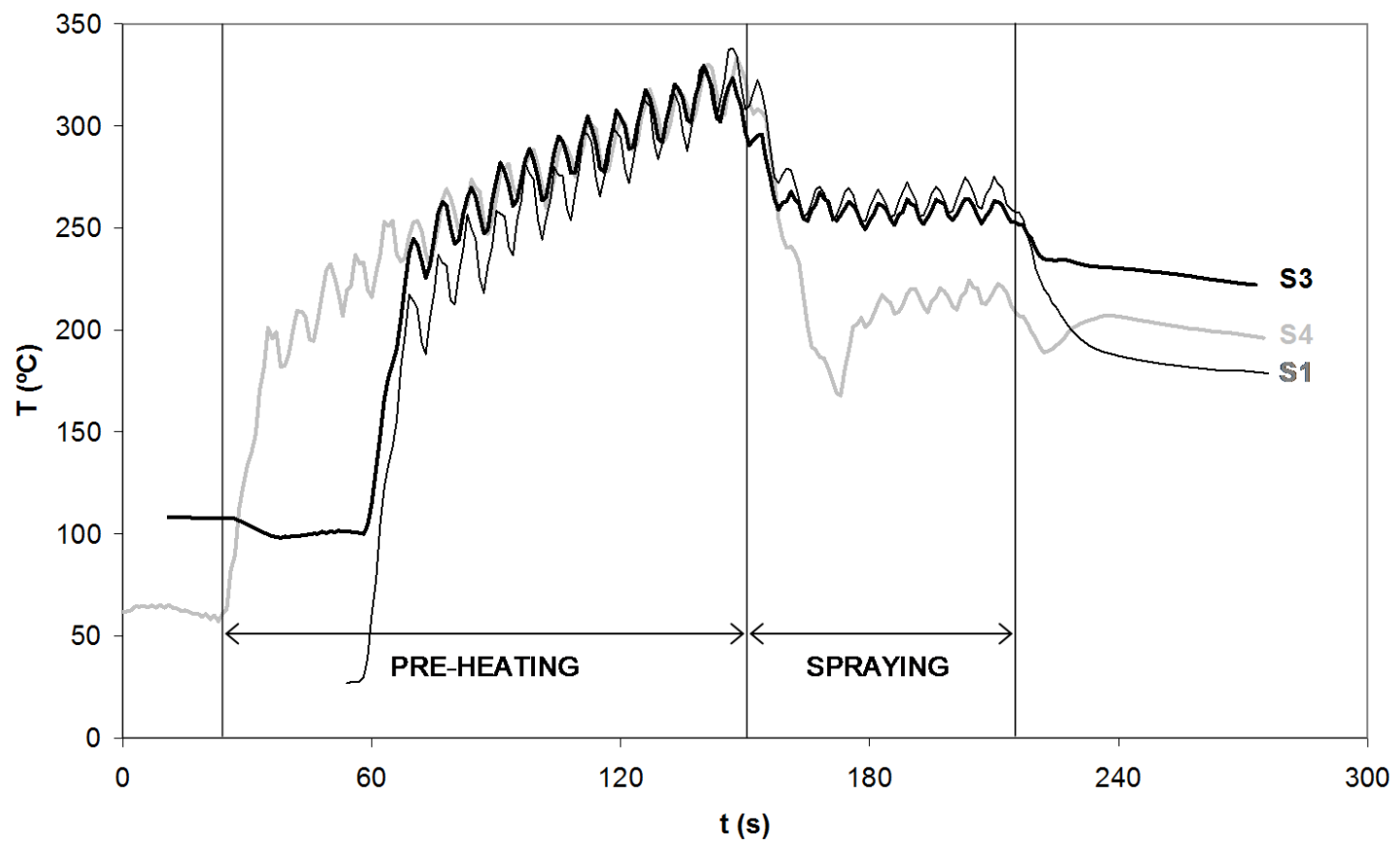

Figure 2 


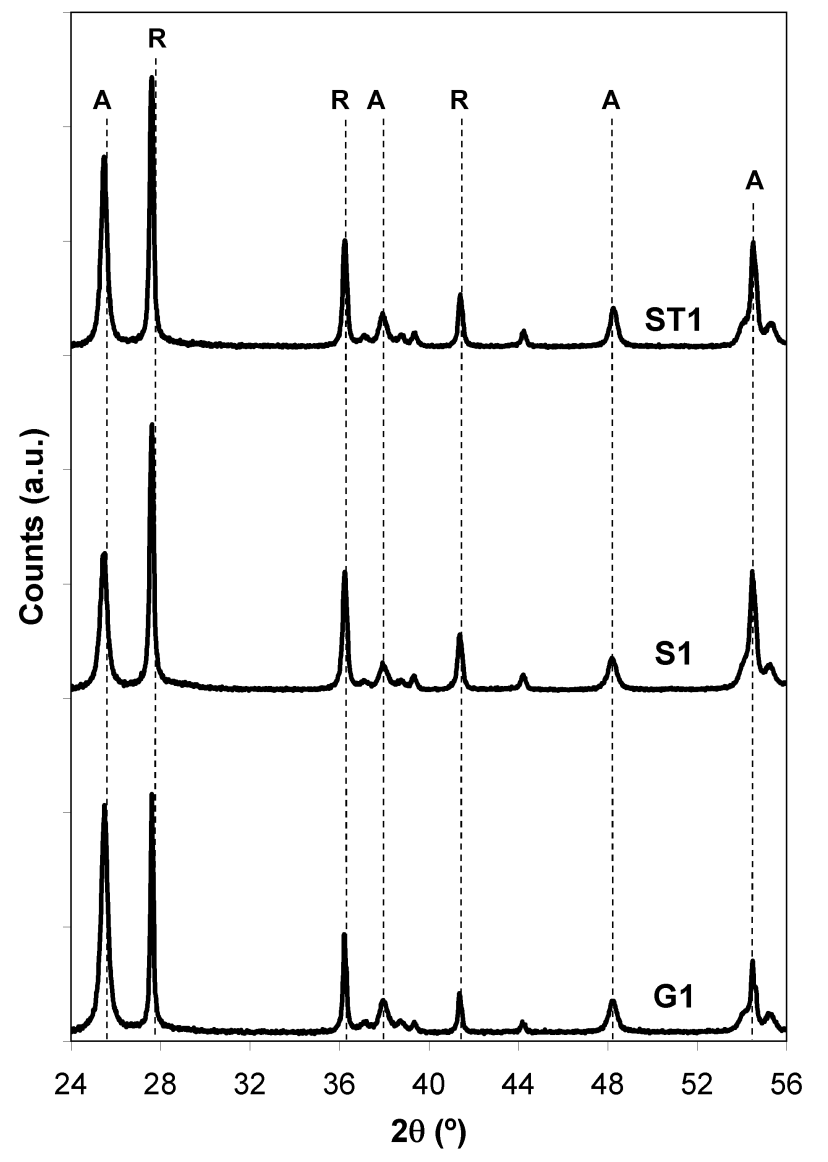

Figure 3 


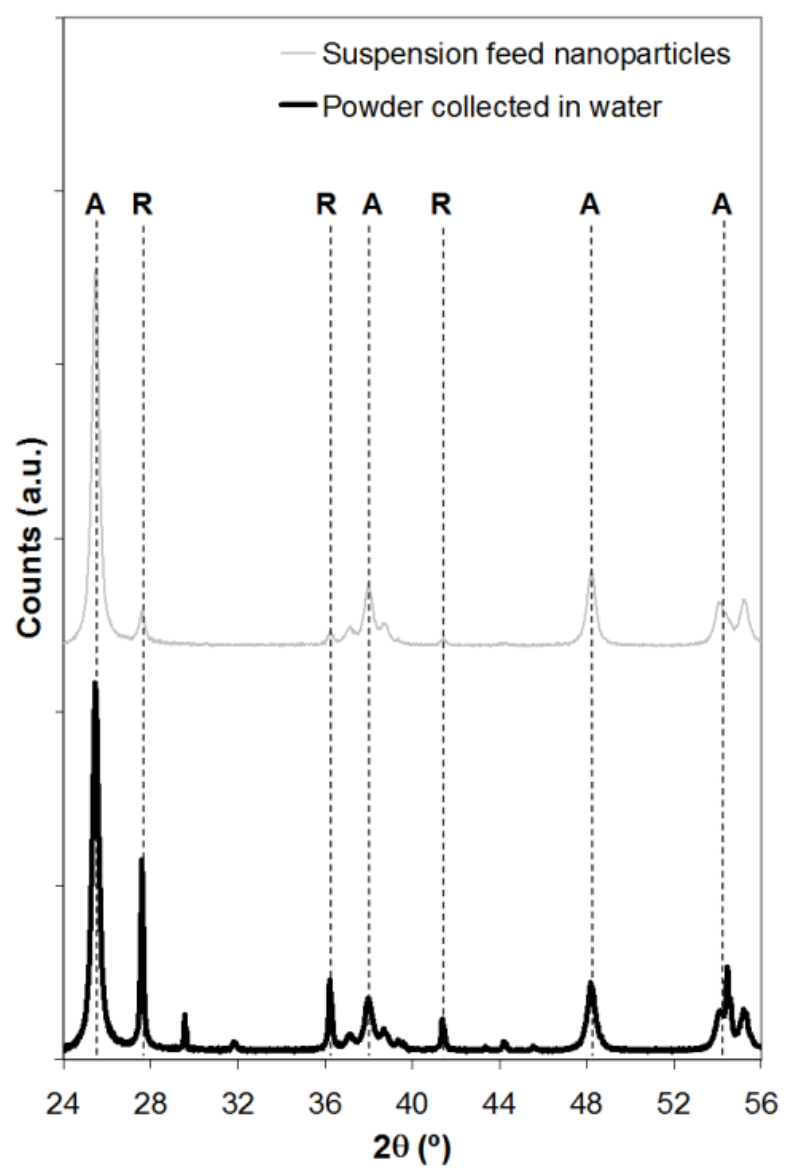

Figure 4 


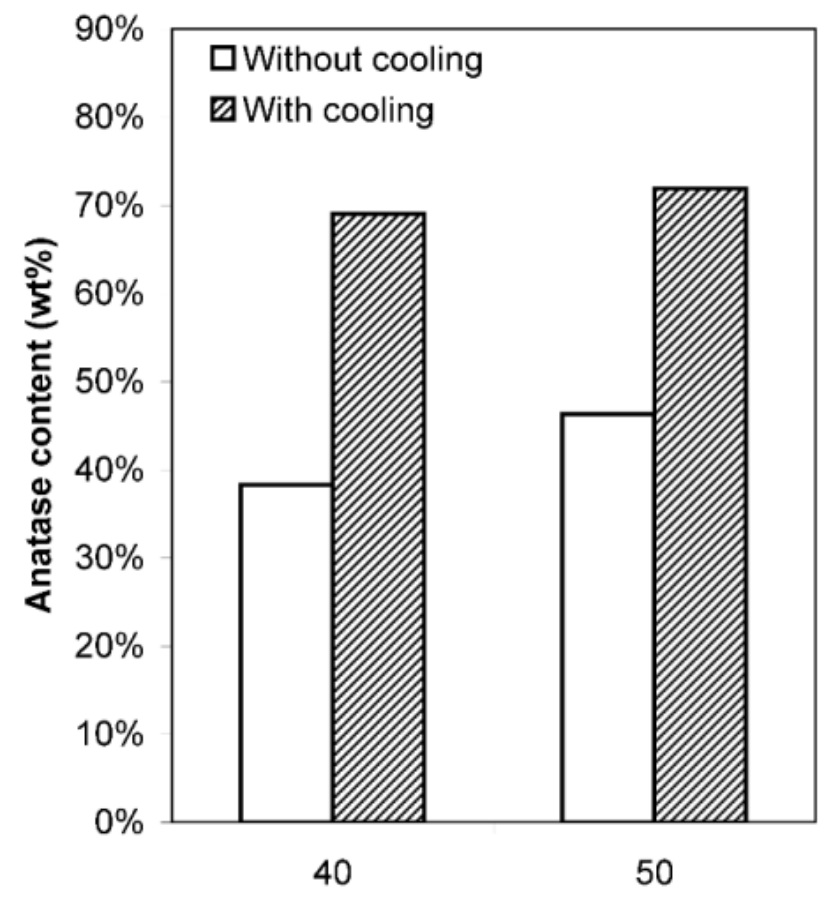

Spraying distance $(\mathrm{mm})$

Figure 5

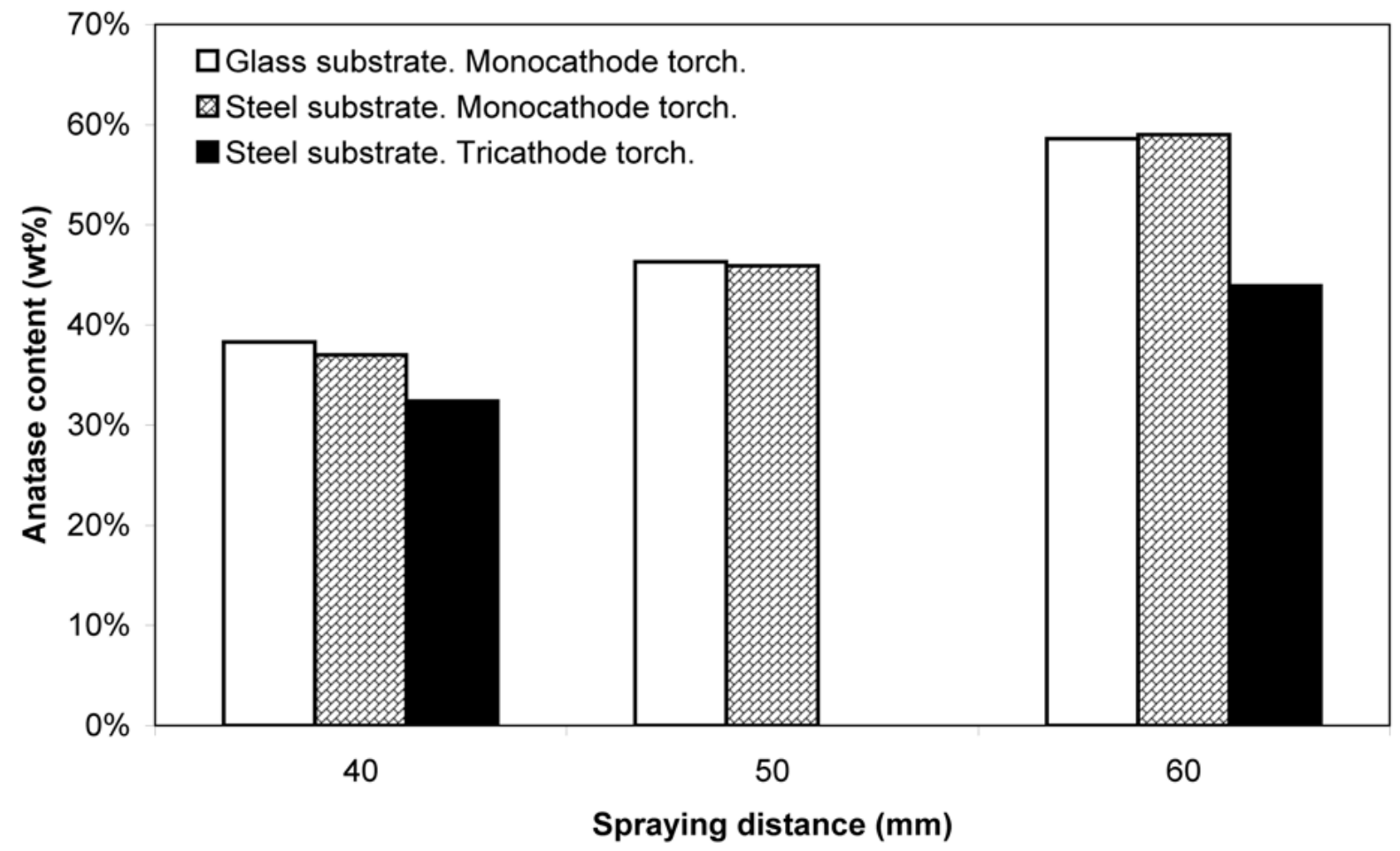

Figure 6 

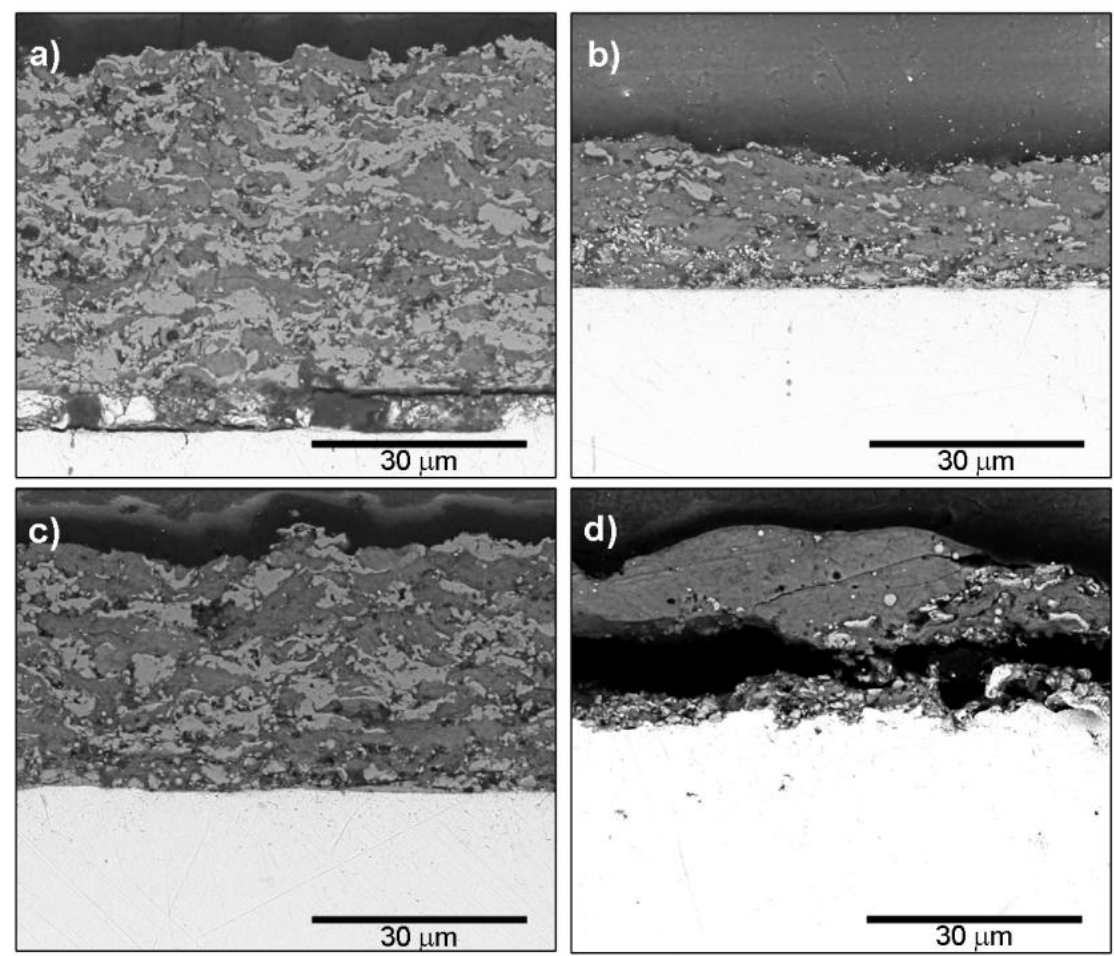

Figure 7
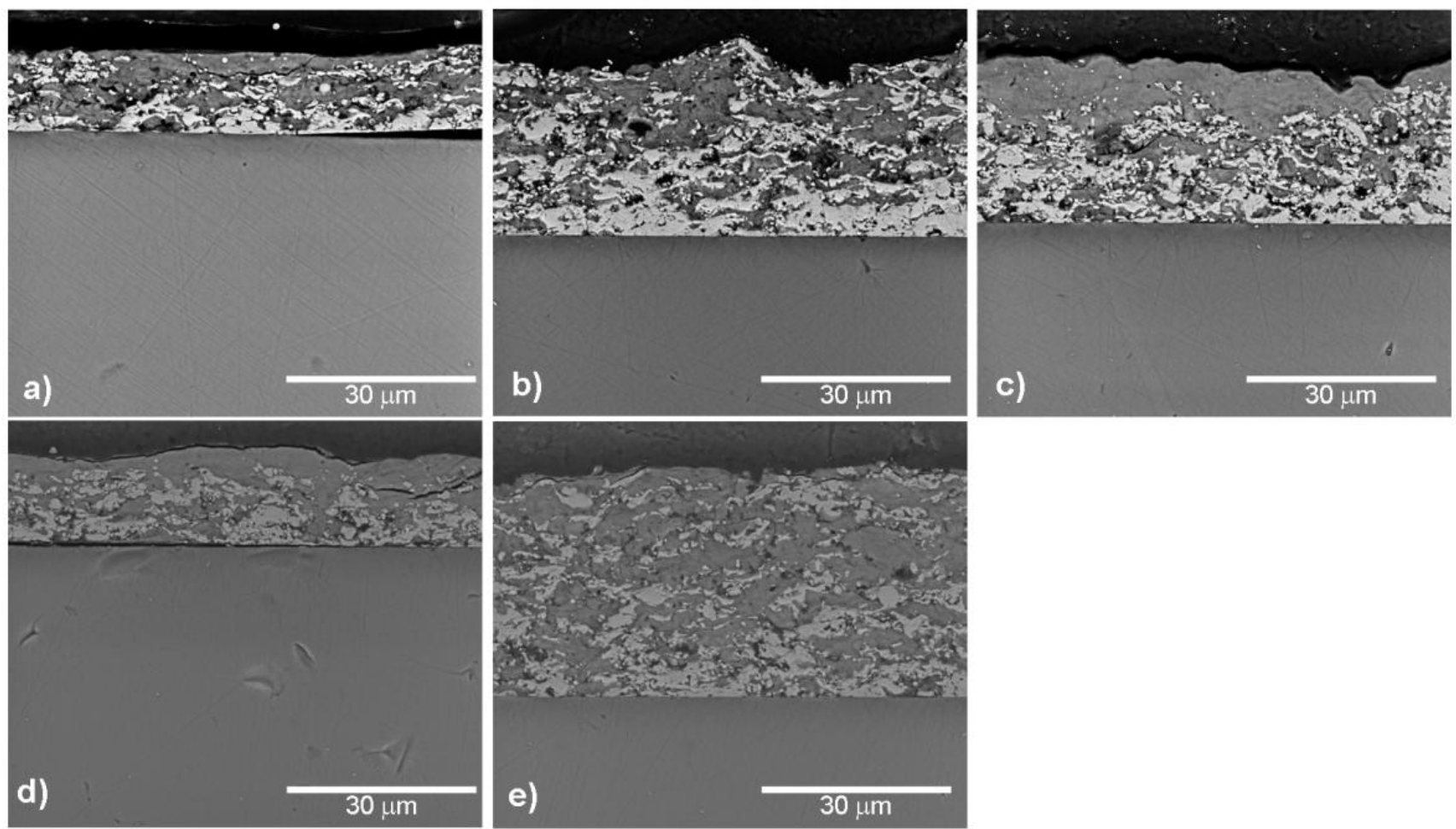

Figure 8 

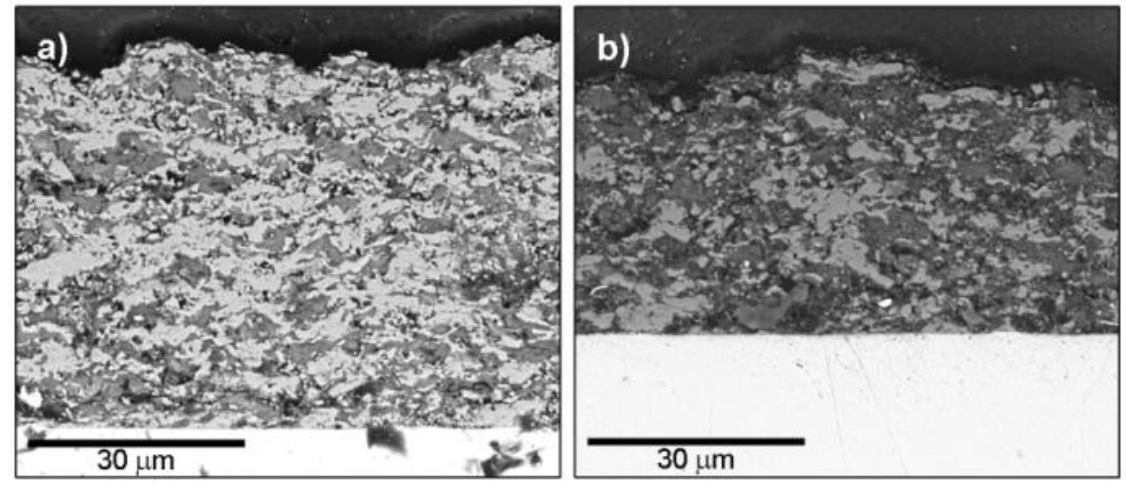

Figure 9
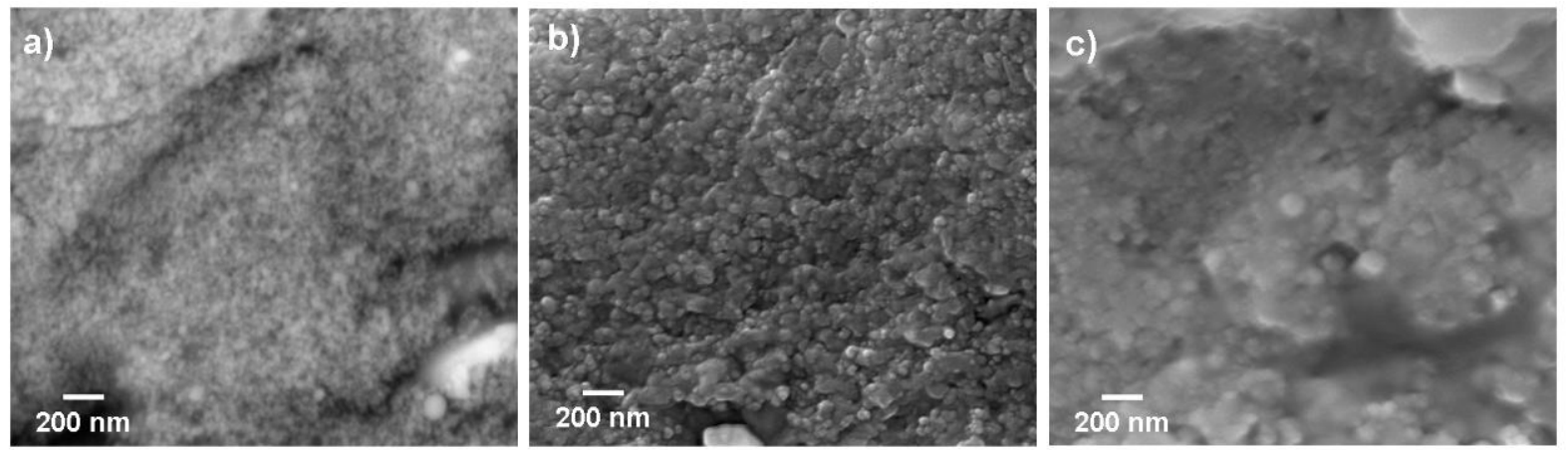

Figure 10
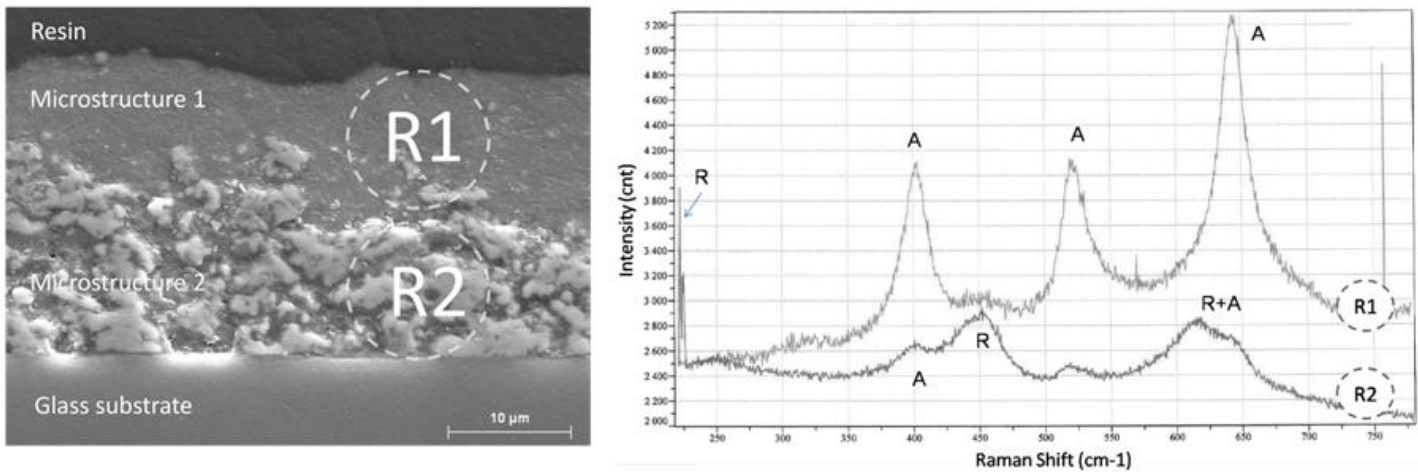

Figure 11 


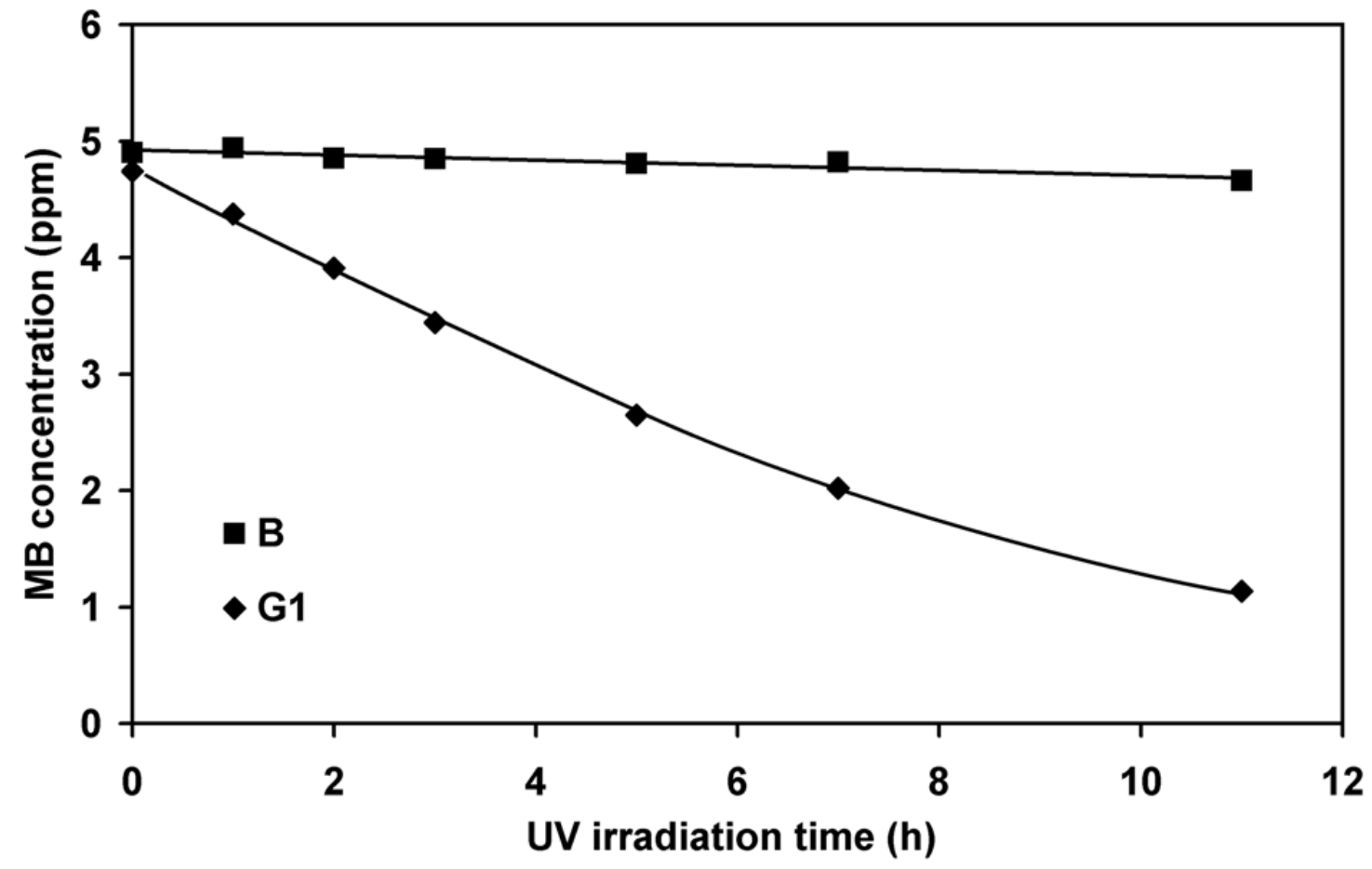

Figure 12

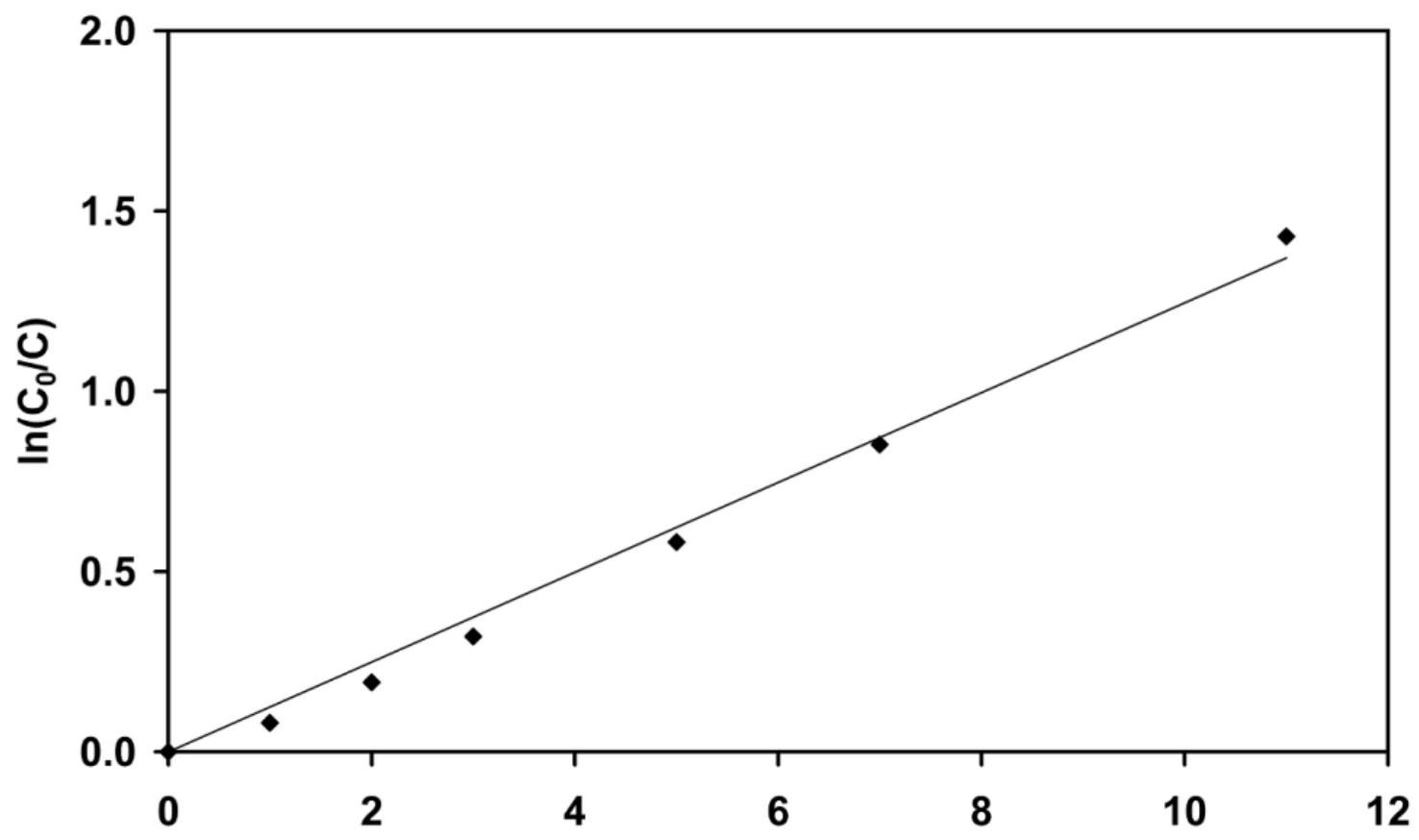

Figure 13 


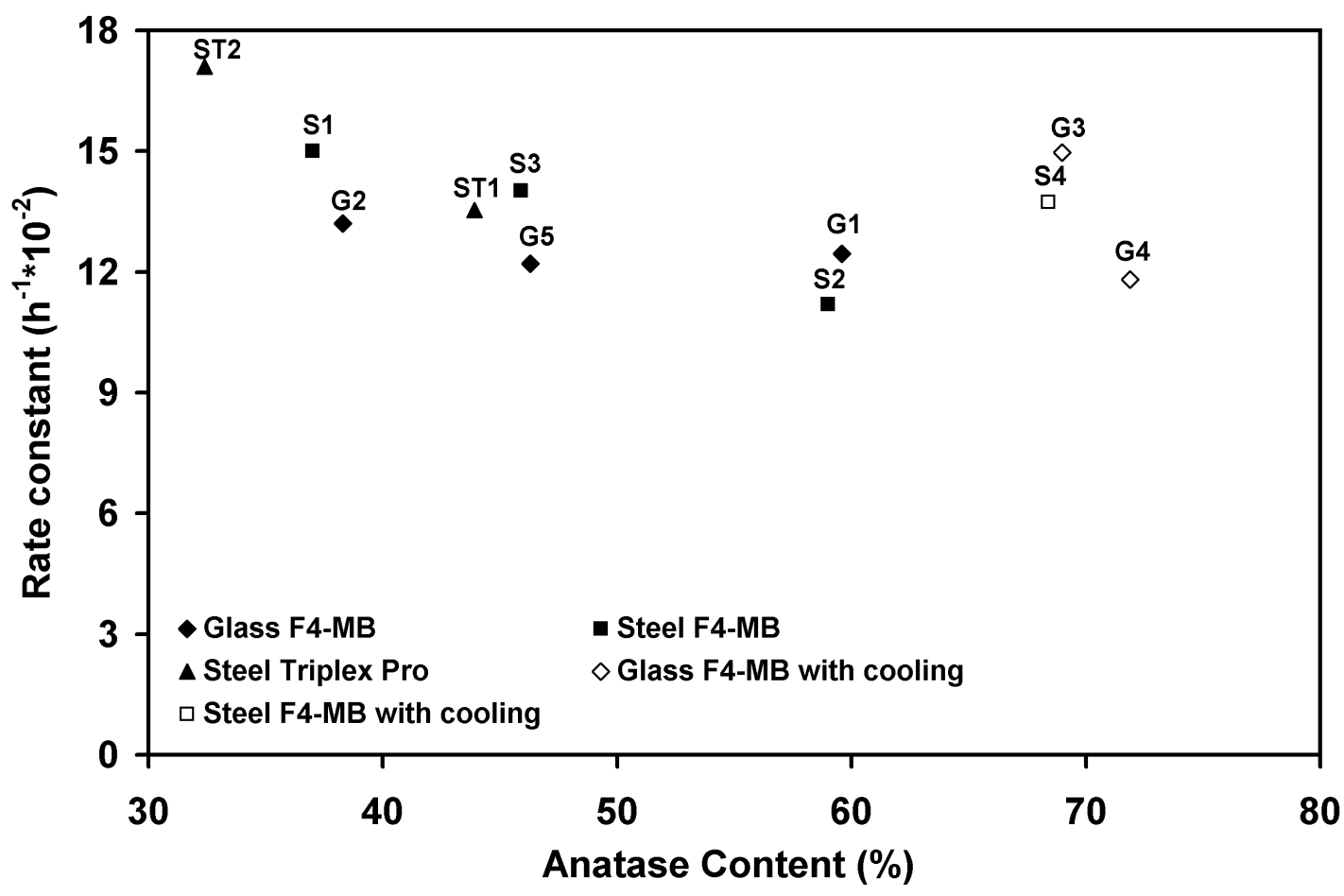

Figure 14 


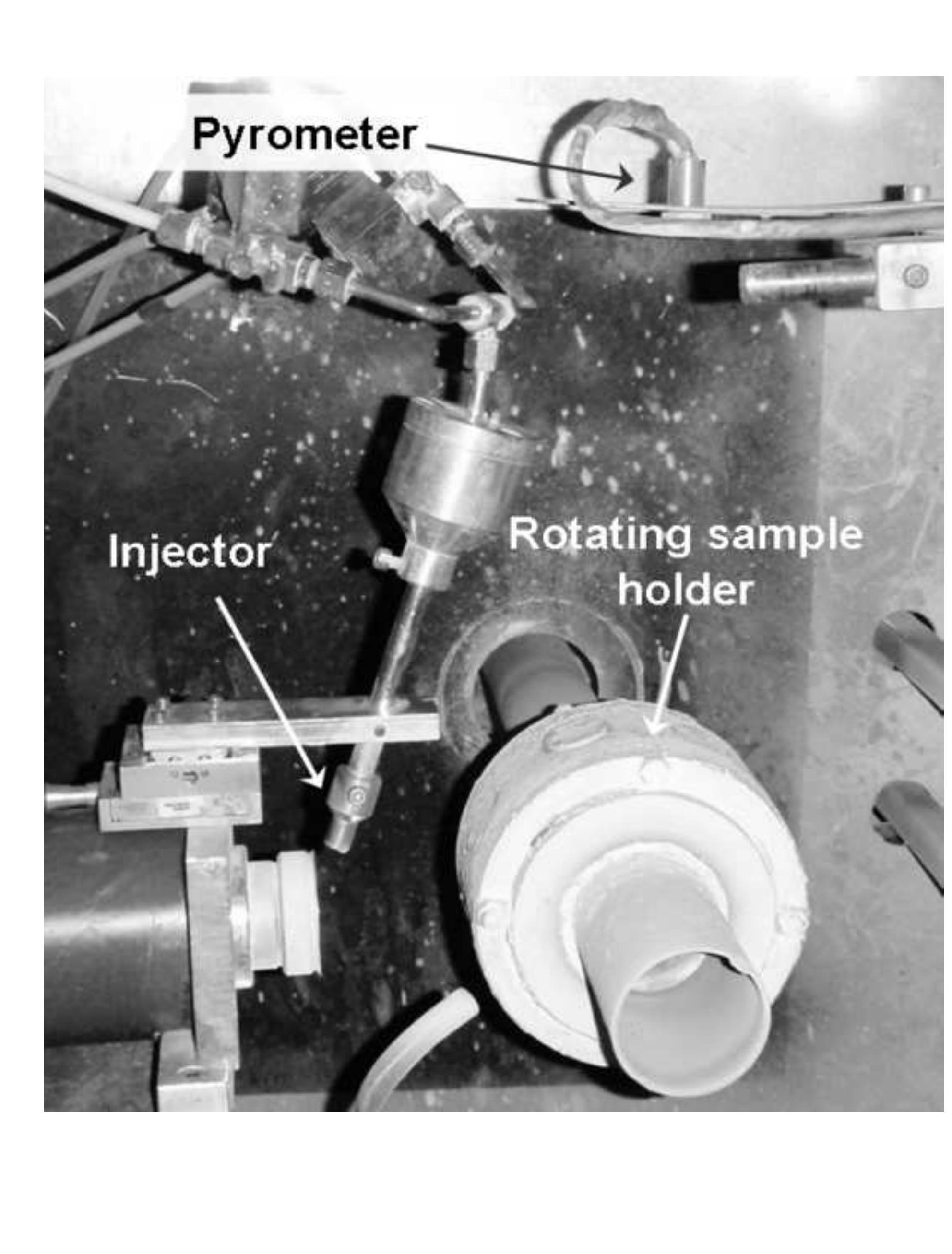

Pyrometer

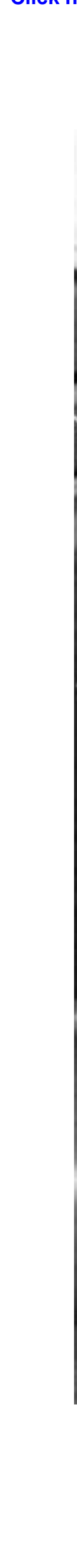




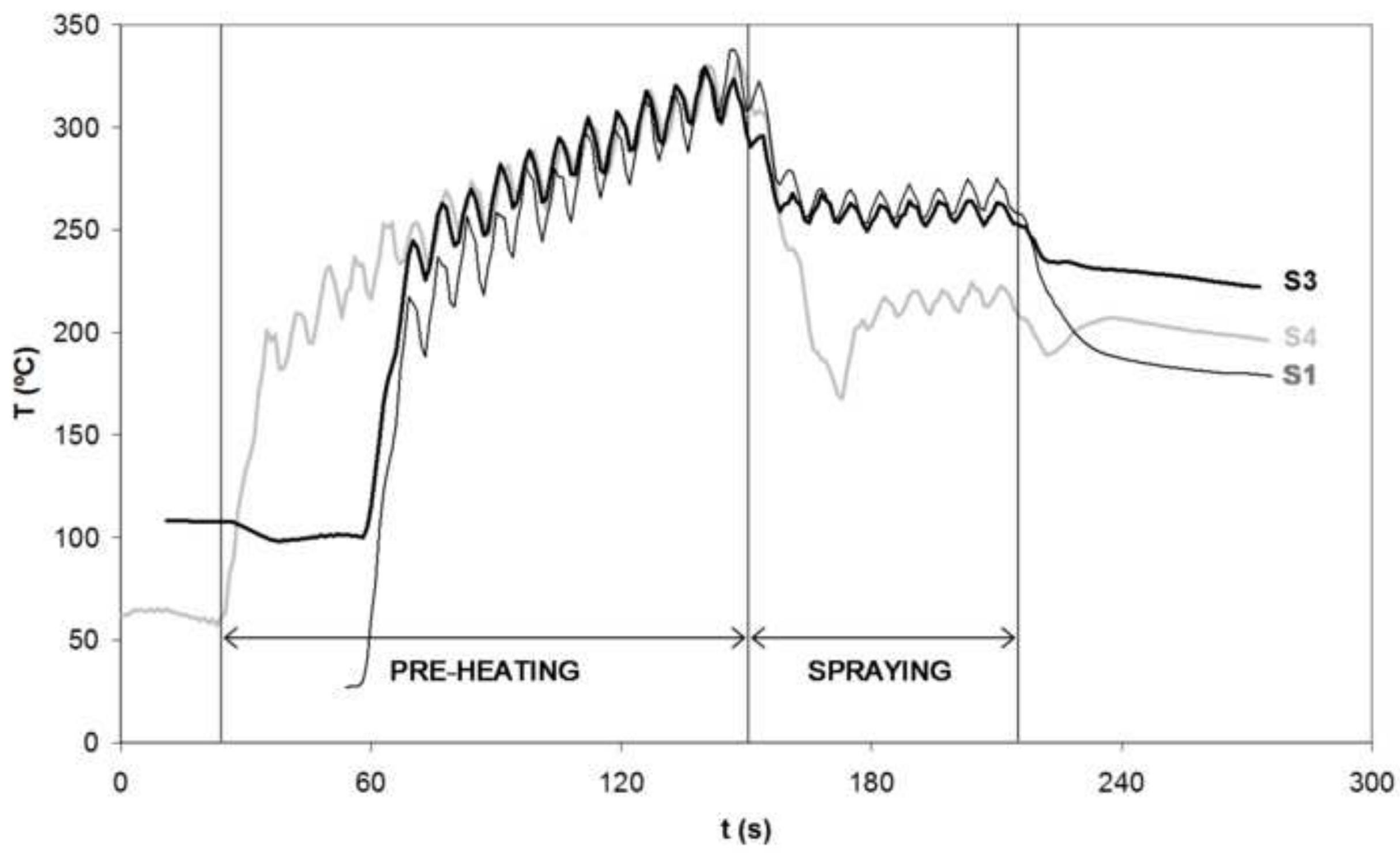


Figure(s)

Click here to download high resolution image

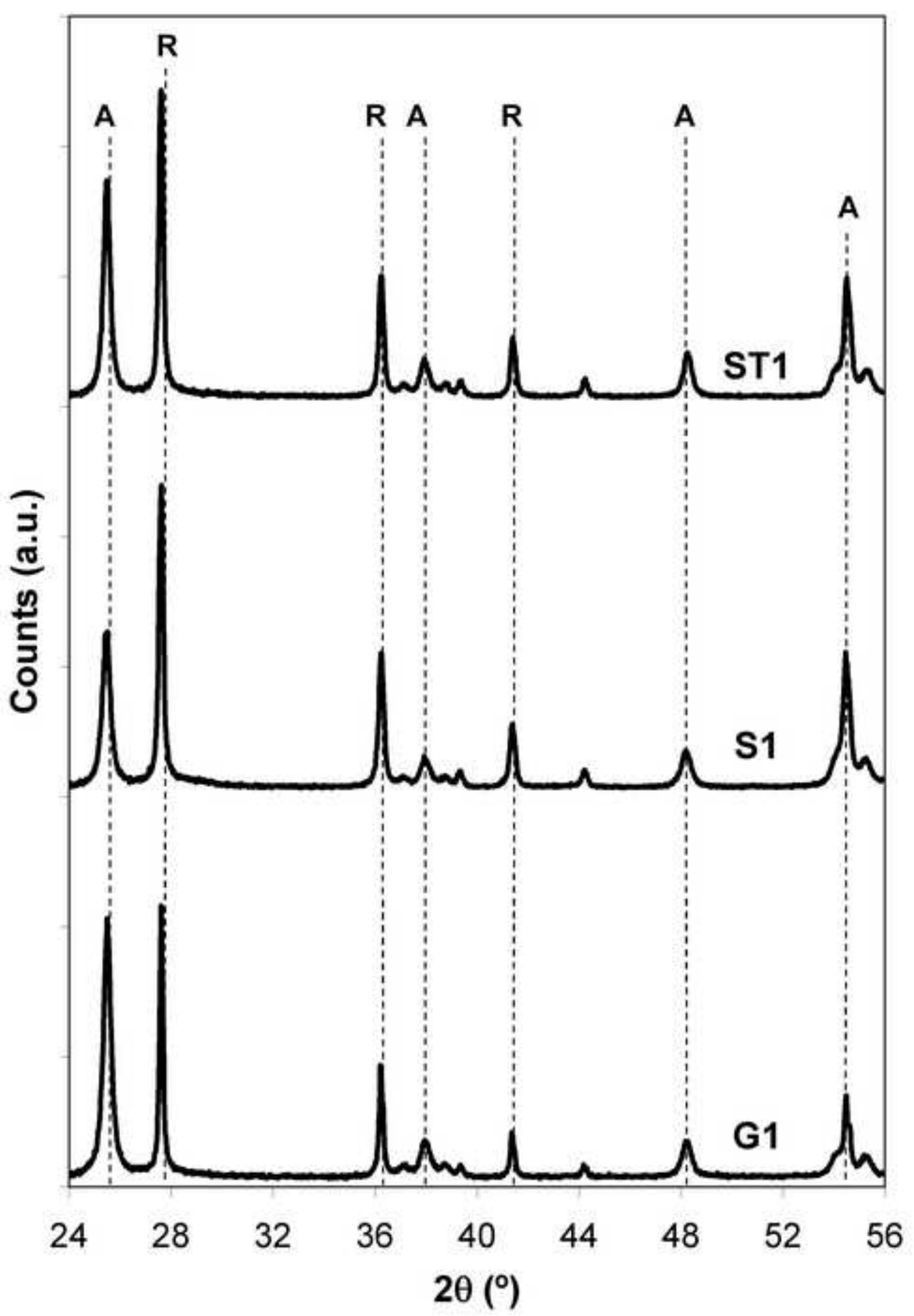




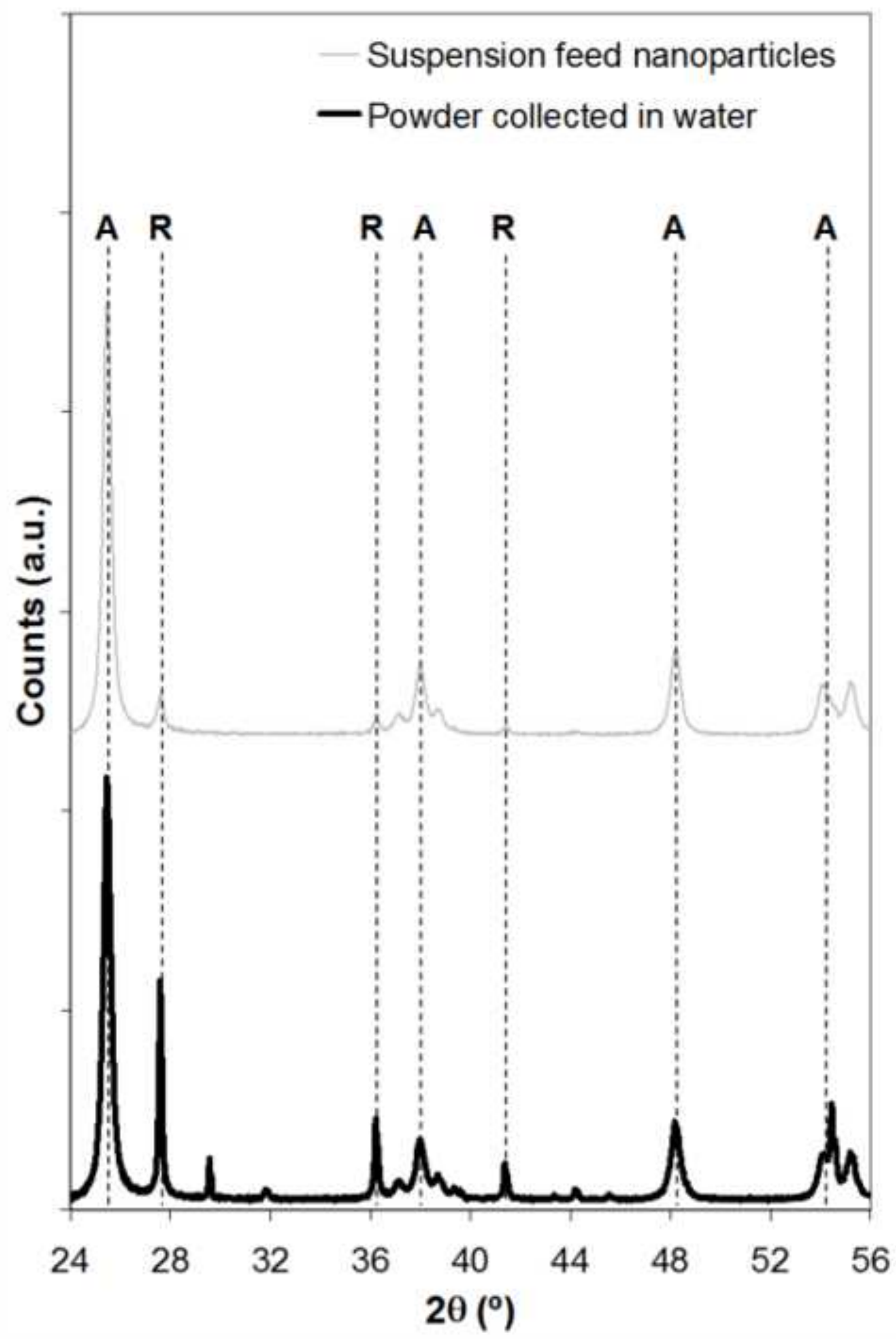


Figure(s)
Click here to download high resolution image

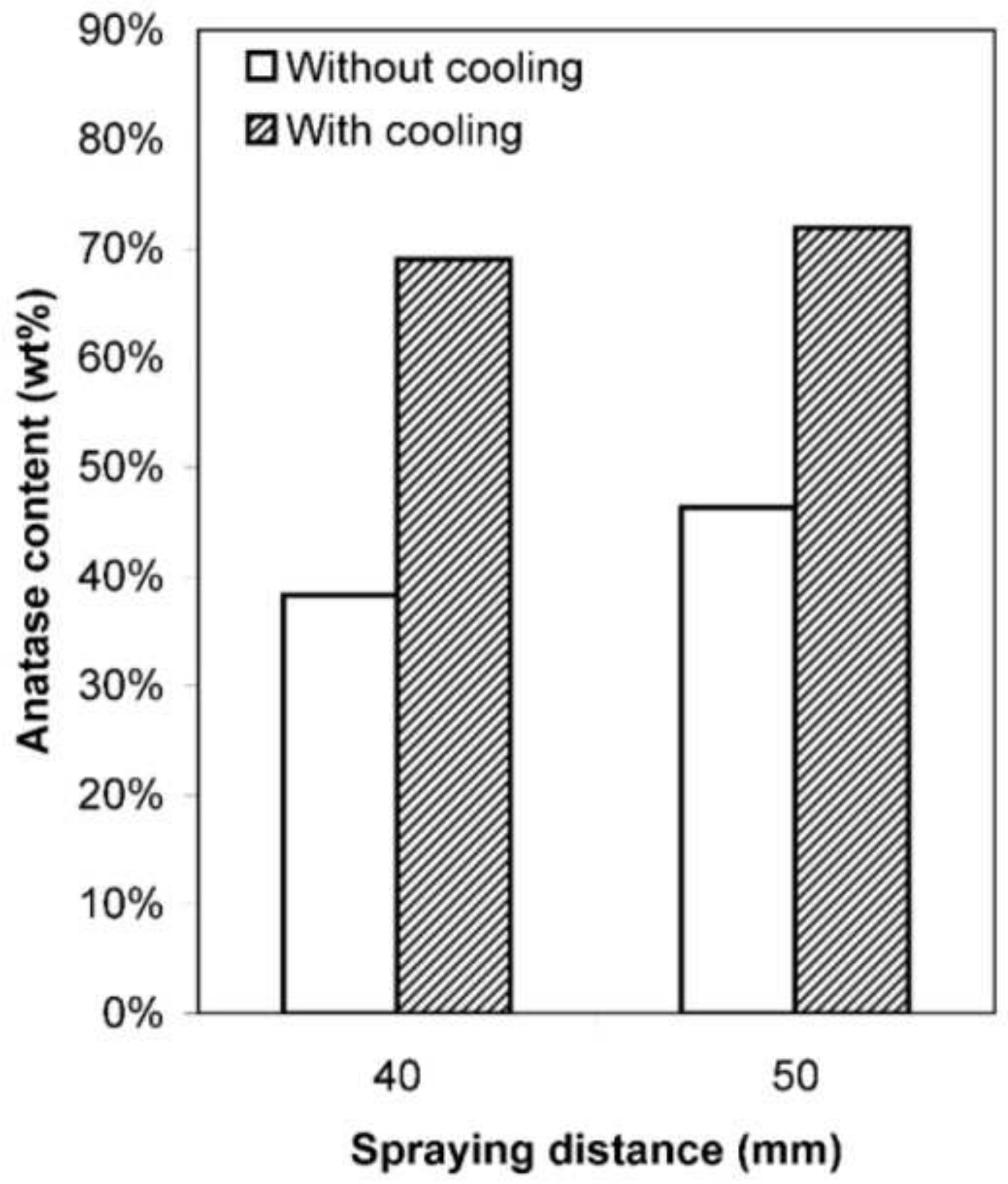




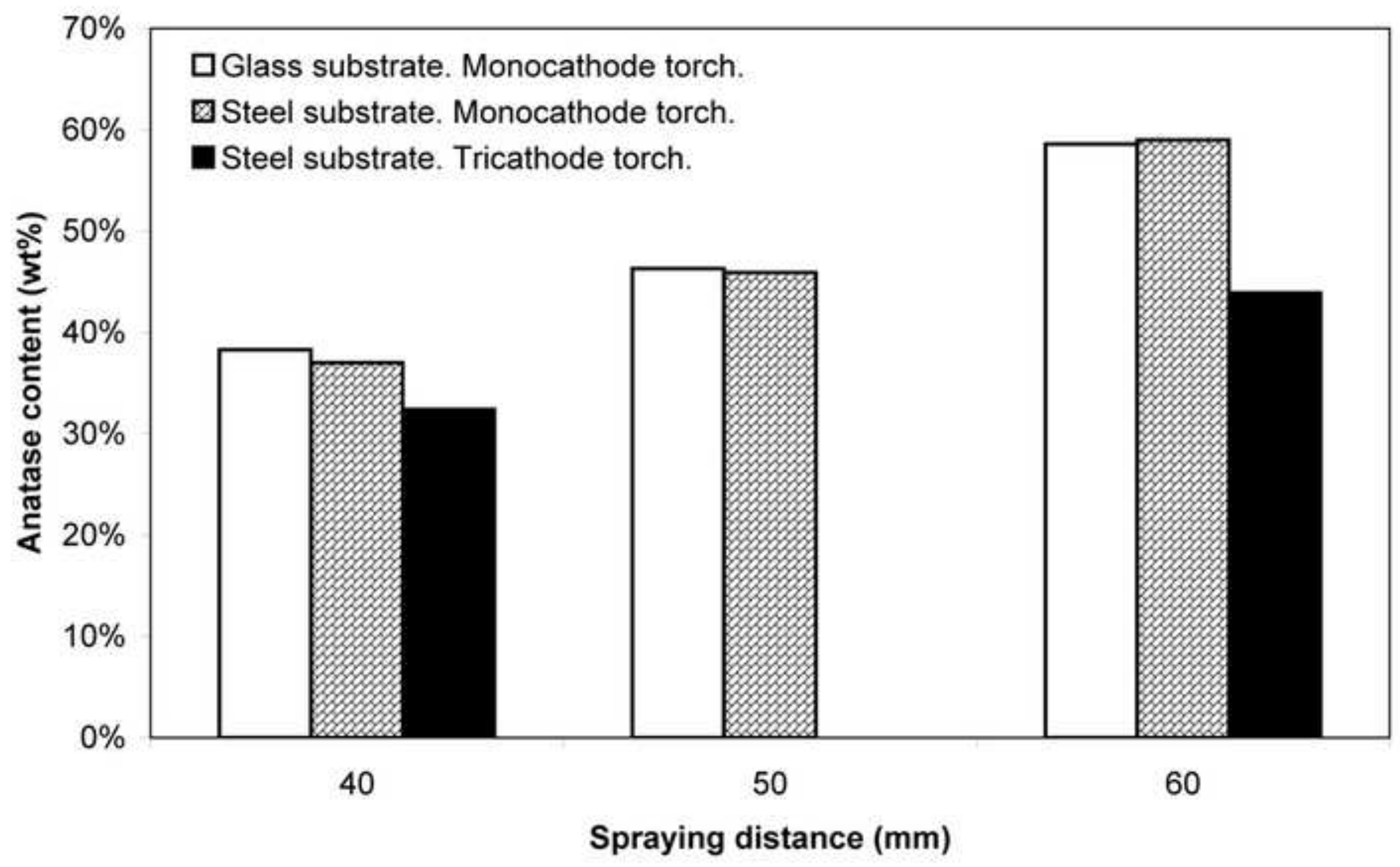




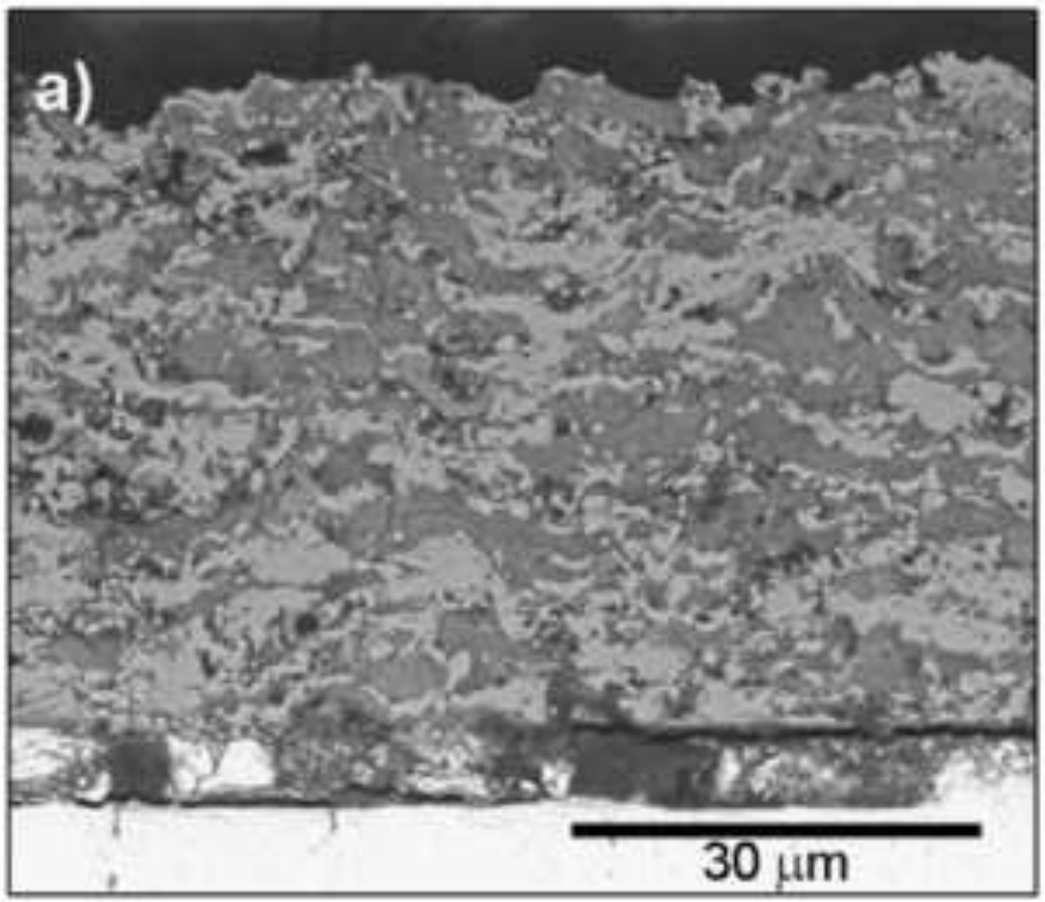

b)
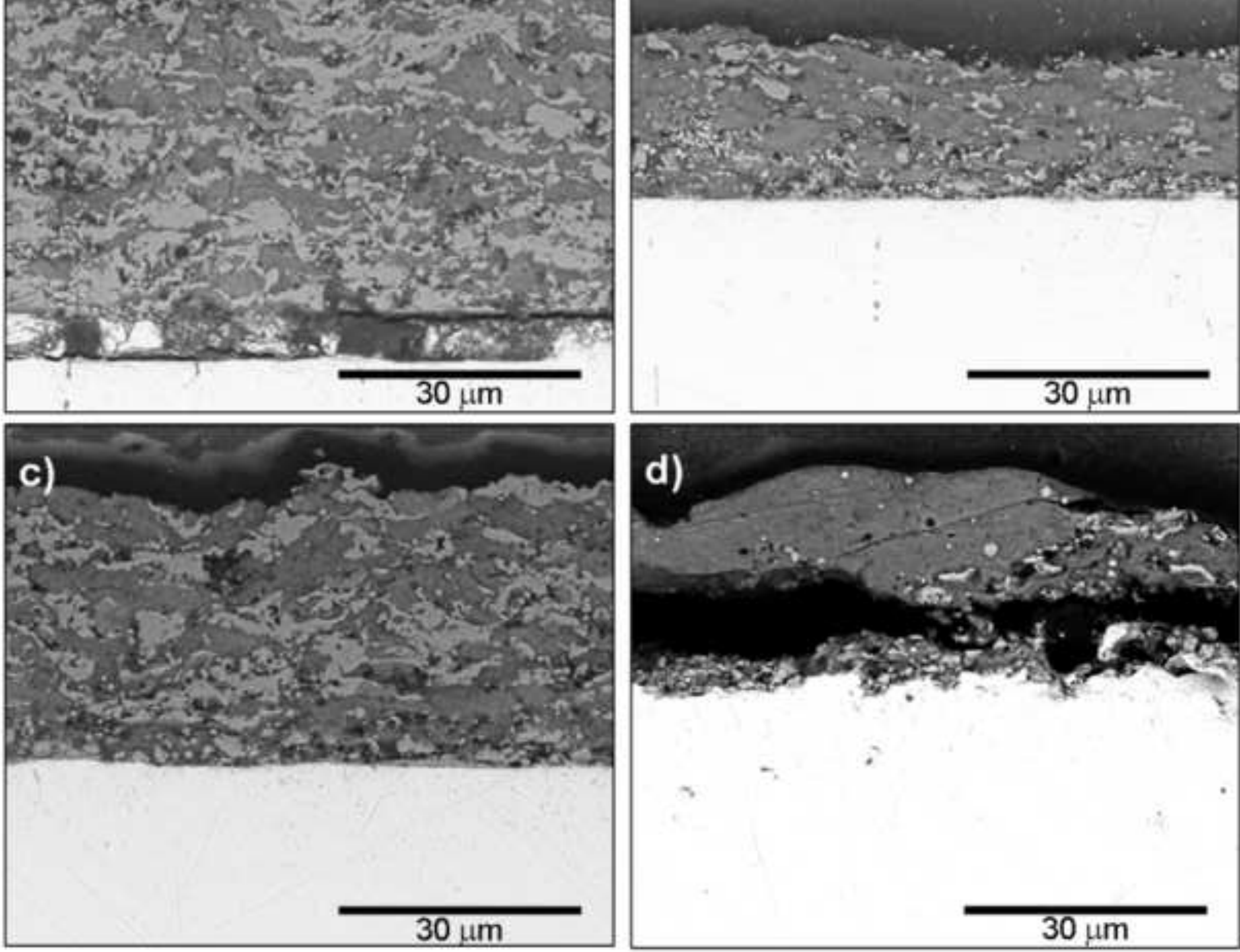
Click here to download high resolution image
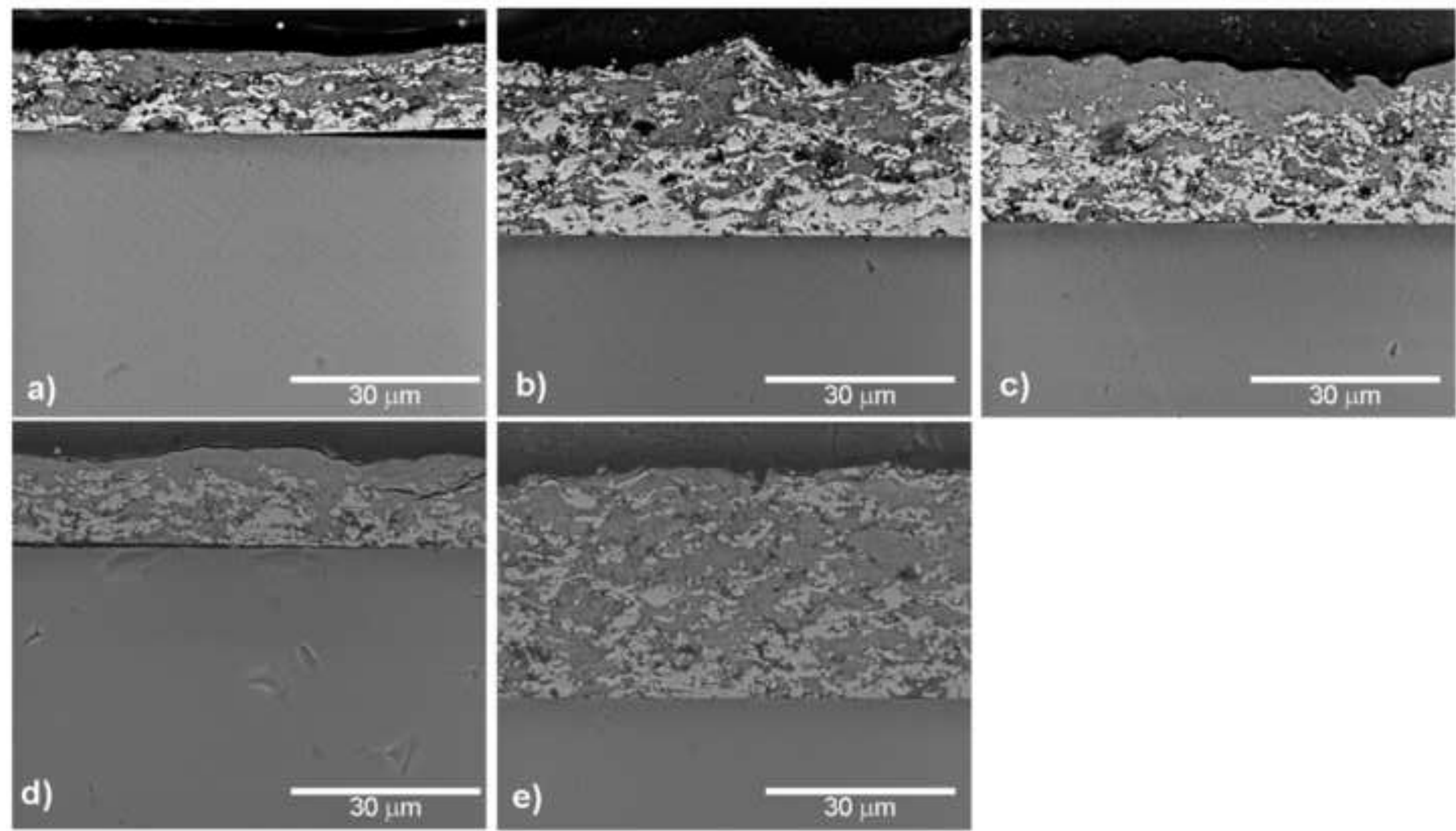

$30 \mu \mathrm{m}$

e)

$30 \mu \mathrm{m}$ 
Click here to download high resolution image
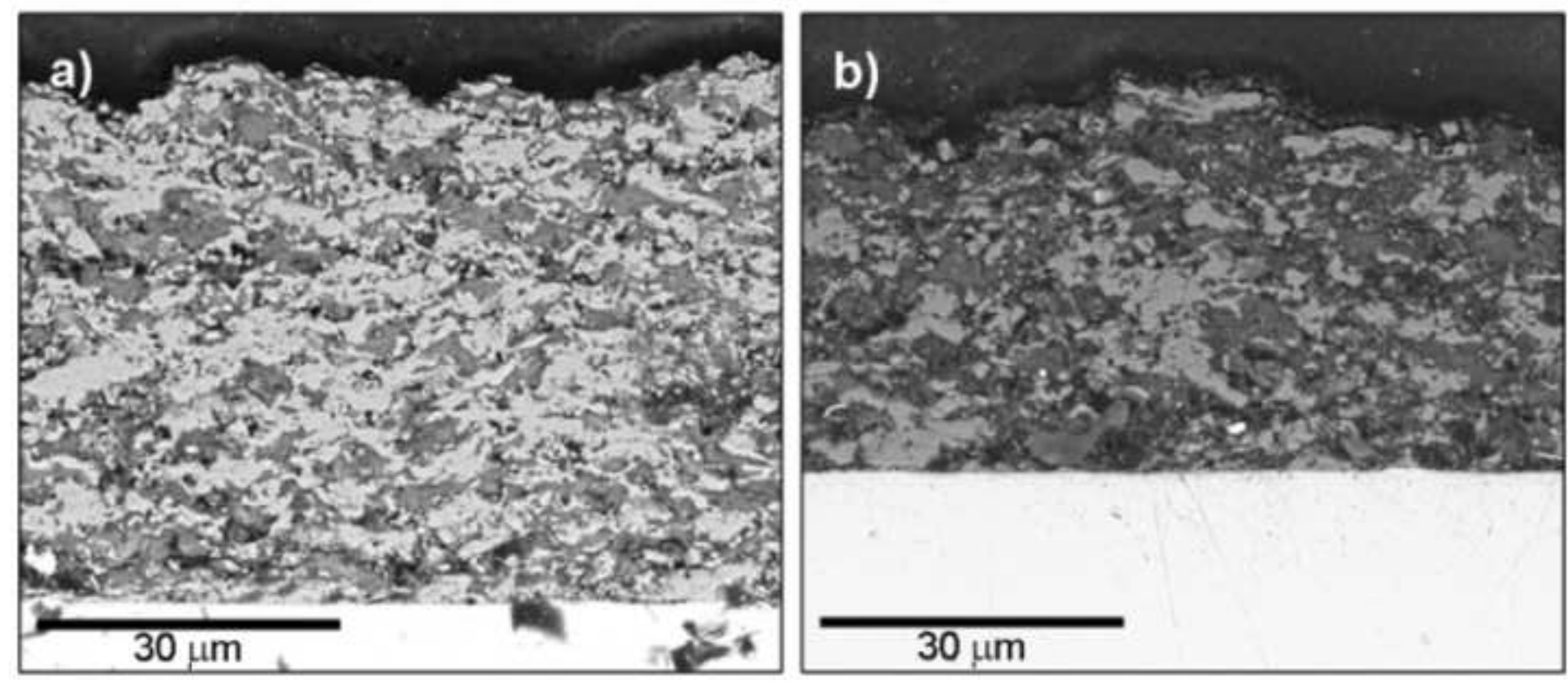
Figure(s)
Click here to download high resolution image
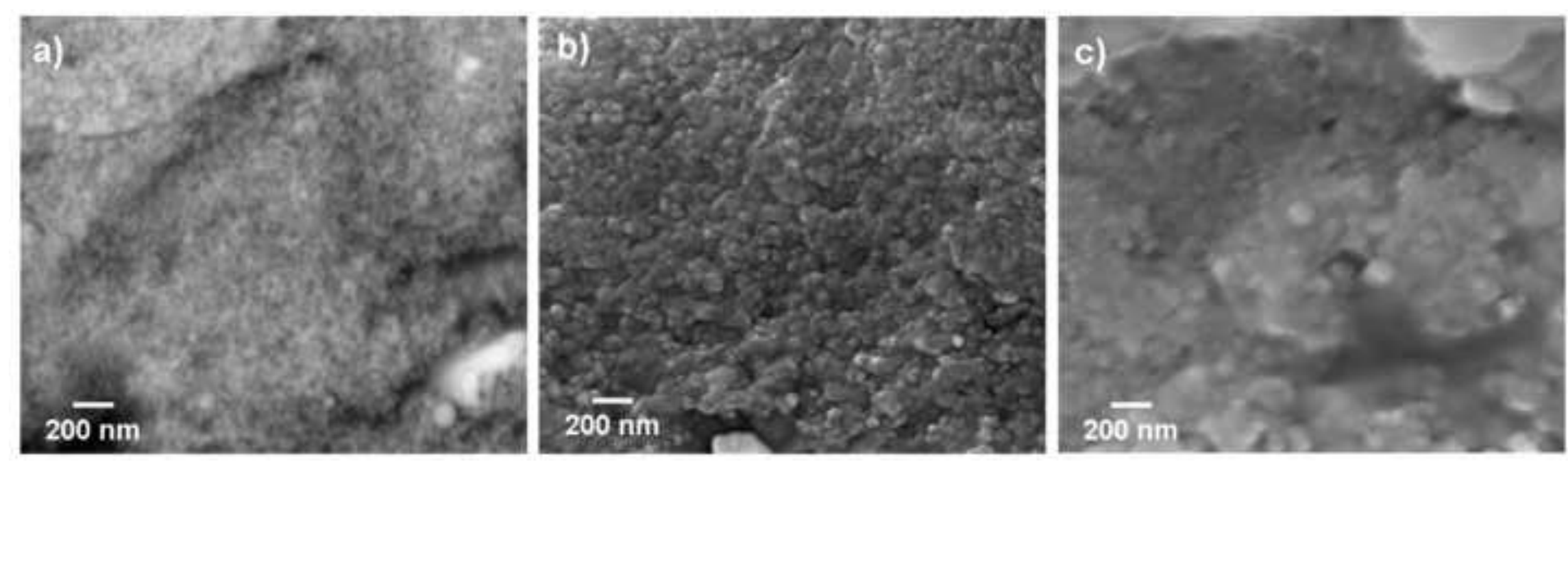
Click here to download high resolution image
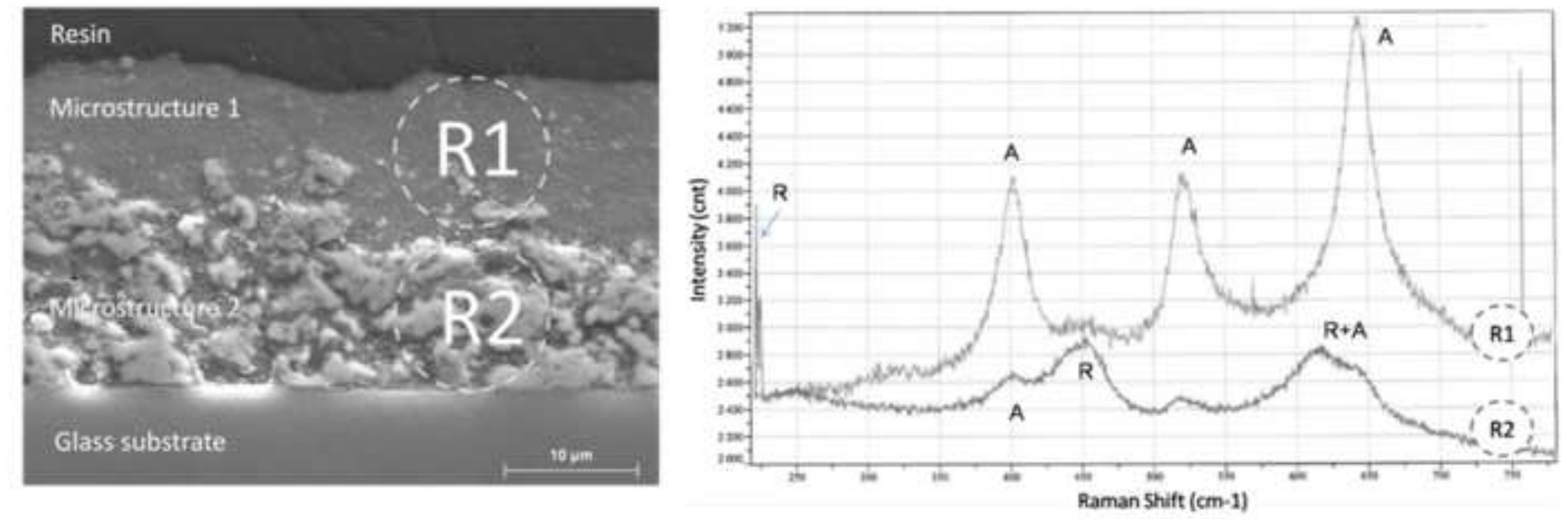


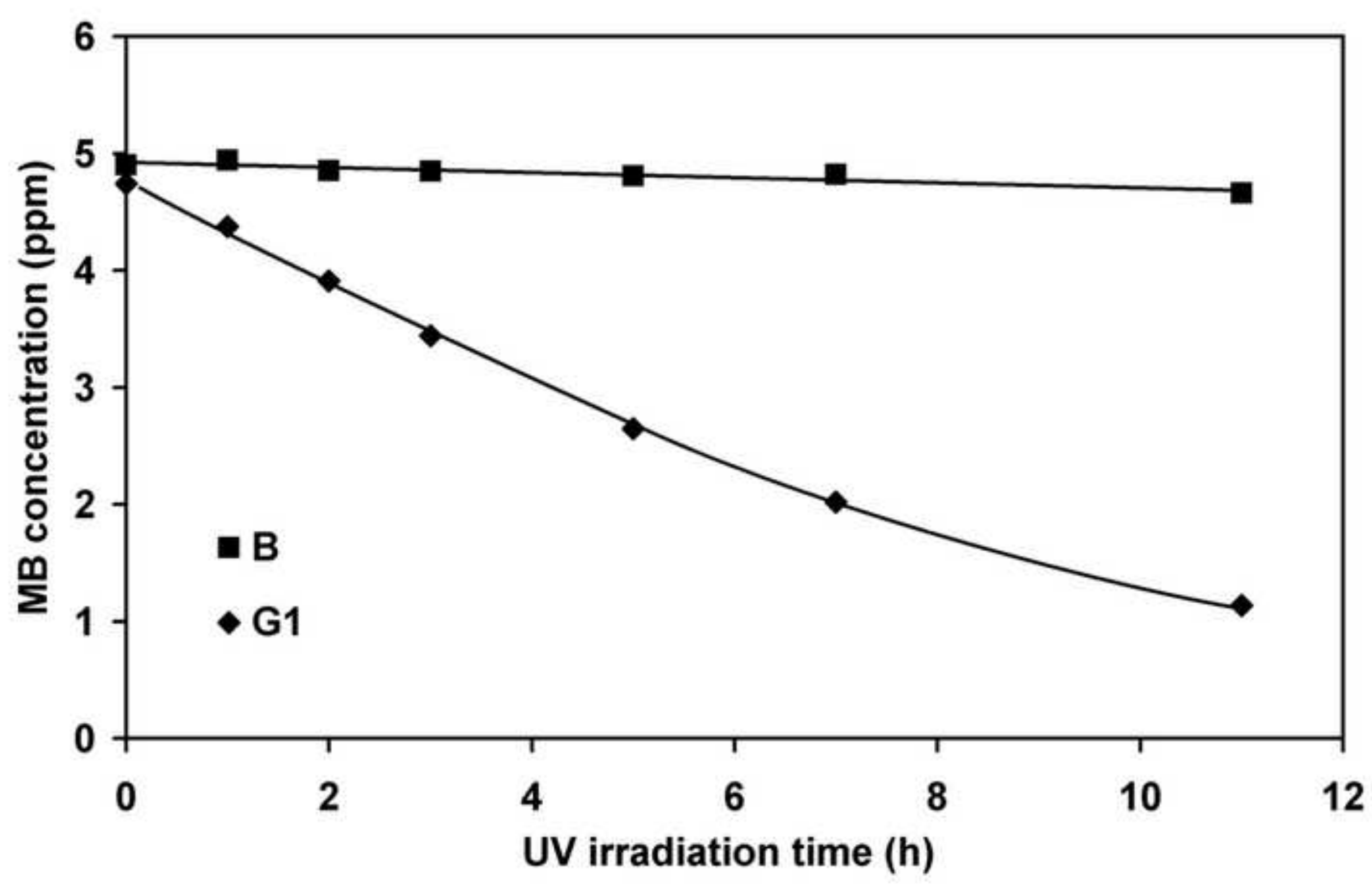

tere 
Click here to download high resolution image

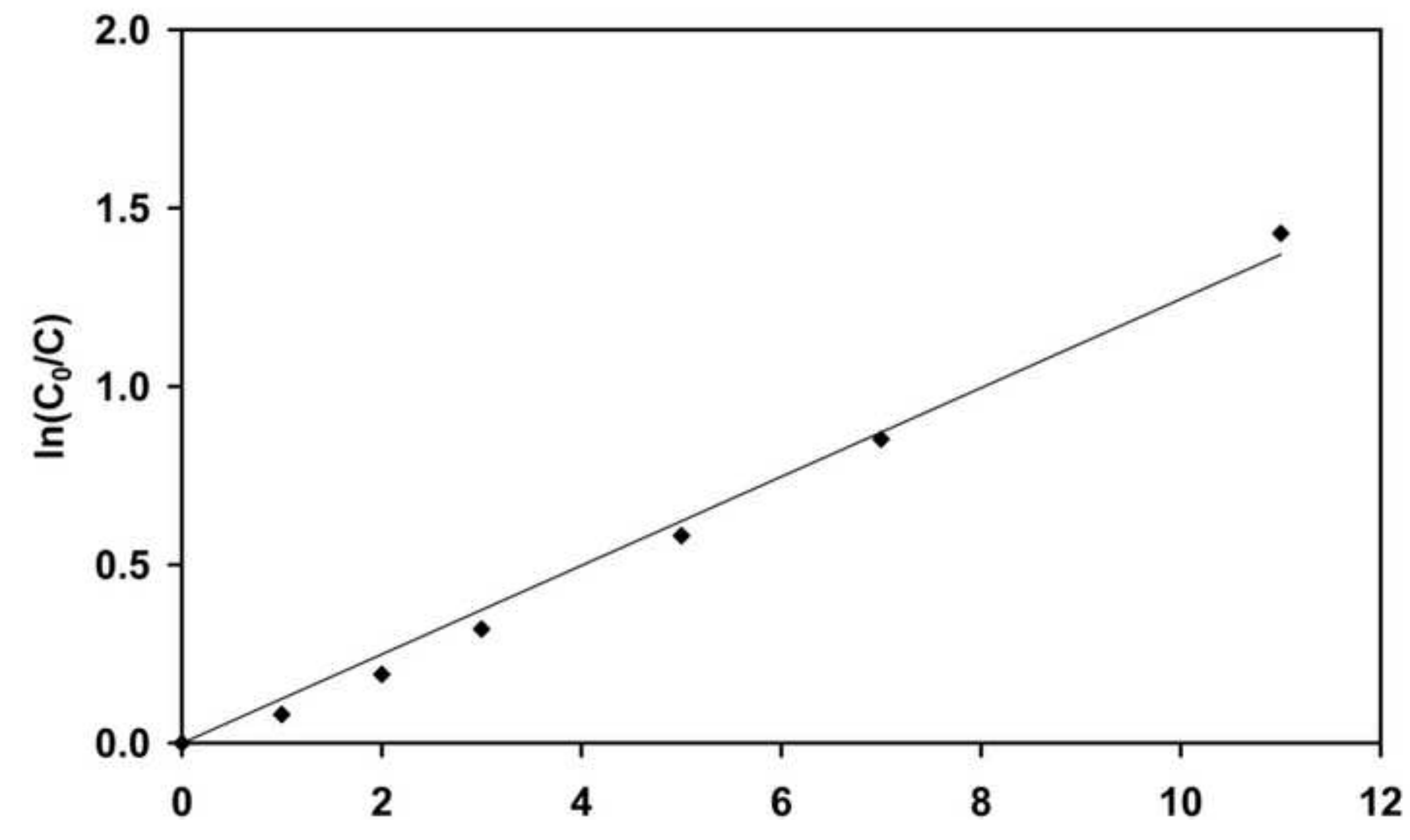

\section{Click here to download high resolution image}




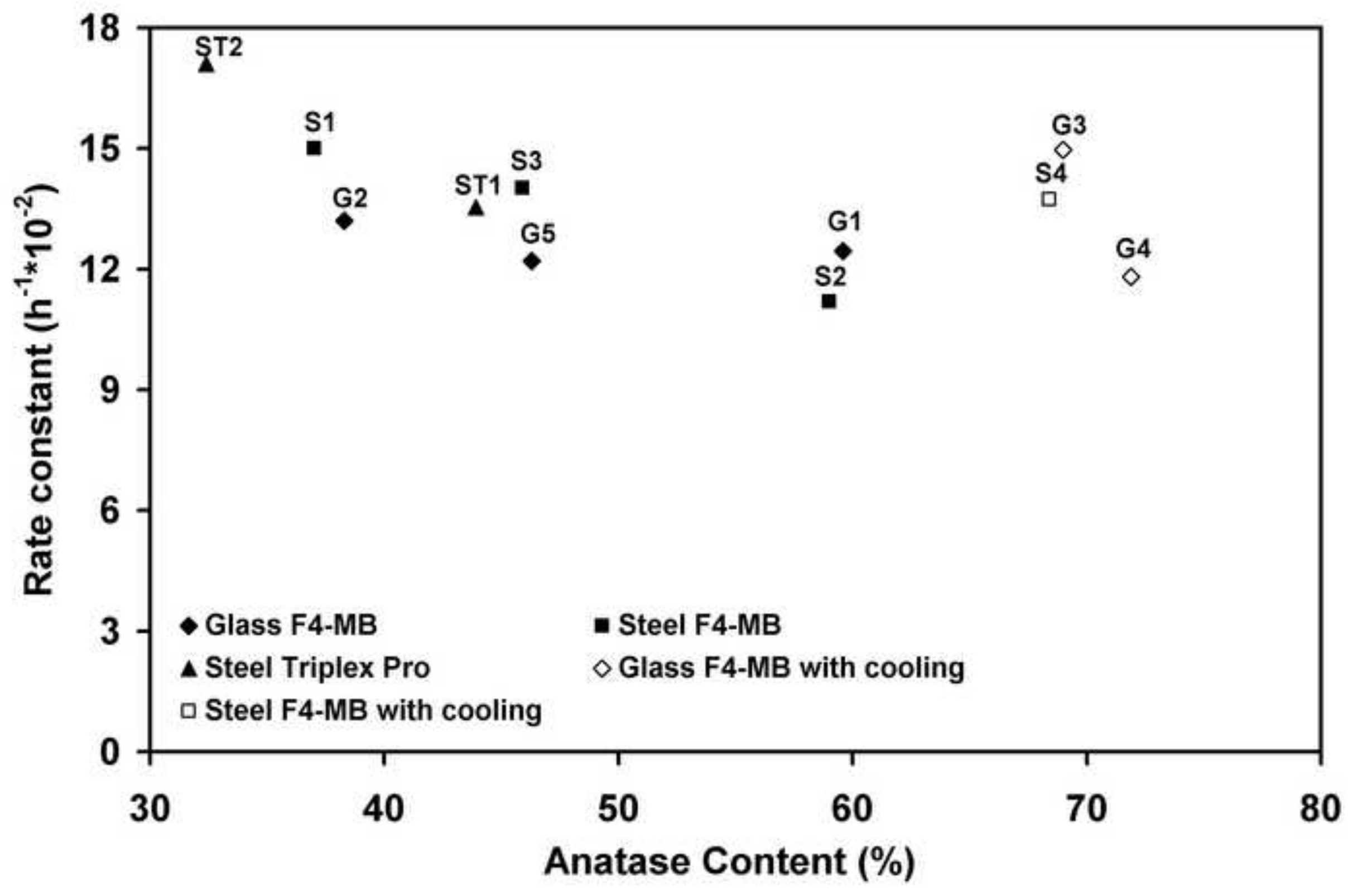

